\title{
Abnormal Indices of Cell Cycle Activity in Schizophrenia and their Potential Association with Oligodendrocytes
}

\author{
Pavel Katsel*,', Kenneth L Davis', Celeste Li', Weilun Tan', Elizabeth Greenstein', Lisa B Kleiner Hoffman' \\ and Vahram Haroutunian ${ }^{1,2}$ \\ 'Department of Psychiatry, The Mount Sinai School of Medicine, New York, NY, USA; and ${ }^{2} J$ J Peters VA Medical Center, Bronx, NY, USA
}

\begin{abstract}
The goal of this study was to determine what signaling pathways may elicit myelin-specific gene expression deficits in schizophrenia (SZ). Microarray analyses indicated that genes associated with canonical cell cycle pathways were significantly affected in the anterior cingulate gyrus (ACG), the region exhibiting the most profound myelin-specific gene expression changes, in persons with $S Z(N=16)$ as compared with controls $(N=19)$. Detected gene expression changes of key regulators of $\mathrm{GI} / \mathrm{S}$ phase transition and genes central to oligodendrocyte differentiation were validated using APCR in the ACG in an independent cohort ( $N s=45 / 34)$. The relative abundance of phosphorylated retinoblastoma protein ( $\mathrm{PRb}$ ) was increased in the white matter underlying the ACG in SZ subjects (Ns $=12)$. The upregulation of cyclin DI gene expression and the downregulation of $\mathrm{p} 57^{\text {Kip22 }}$, accompanied by increased cyclin D/CDK4-dependent phosphorylation of pRb, acting as a checkpoint for GI/S phase transition, suggest abnormal cell cycle re-entry in postmitotic oligodendrocytes in SZ. Furthermore, gene expression profiling of brain samples from myelin mutant animal models, quaking and myelinassociated glycoprotein (MAG) null mice, showed that cell cycle gene expression changes were not a necessary consequence of the reduced gene expression of structural myelin proteins, such as MAG. While, quaking, a known modulator of cell cycle activity during oligodendrocyte differentiation impairs the expression of multiple myelin genes, including those that are affected in SZ. These data suggest that the normal patterns of cell cycle gene and protein expression are disrupted in $\mathrm{SZ}$ and that this disruption may contribute to the oligodendroglial deficits observed in SZ.
\end{abstract}

Neuropsychopharmacology (2008) 33, 2993-3009; doi:1 0.1038/npp.2008.19; published online 5 March 2008

Keywords: schizophrenia; gene expression; oligodendrocyte; myelin; cingulate cortex; cell cycle

\section{INTRODUCTION}

Disconnection or aberrant communication among different brain regions is believed to contribute to the abnormal functioning of neural networks and has been postulated to be central to the pathophysiology of SZ (Weinberger, 1995; Friston and Frith, 1995; Weinberger and Lipska, 1995; Arnold and Trojanowski, 1996; Raedler et al, 1998; Haroutunian and Davis, 2000; Davis et al, 2003). The neurobiological substrates of these connectivity and communication abnormalities remain unknown, but recent evidence suggests that abnormalities in myelination and altered oligodendrocyte (OLG) number and function may be prominent contributors to $S Z$.

Historically, myelination has been viewed as a central process supporting the functional synchrony of neural networks. For example, loss of a single myelinating

\footnotetext{
* Correspondence: Dr P Katsel, Department of Psychiatry, Room 4F20, JJ Peters VA Medical Center, Research Build. (15I), I30 West Kingsbridge Road, Bronx, NY 10468, USA, Tel: + I 7185849000 ext 6067, Fax: + I 718365 9622, E-mail: pavel.katsel@mssm.edu Received 13 November 2007; revised 23 January 2008; accepted 24 January 2008
}

oligodendrocyte may affect the speed of signal conduction and propagation (Baumann and Pham-Dinh, 2001) in as many as 40 axons (Larocca and Rodriguez-Gabin, 2002). Thus, abnormalities in a single oligodendrocyte can be amplified to affect signaling in multiple neurons. In addition, recent animal model studies have implicated OLG involvement in modulating neurotransmission and thus may contribute to disturbances in neurotransmission that are associated with SZ (Roy et al, 2007). For example, OLGs play a significant role not only in regulating glutamate function (Gallo and Ghiani, 2000), but the downregulation of OLG-associated genes has also been shown to affect the levels and metabolism of dopamine in rodent models (Nikulina et al, 1995; Roy et al, 2007). In addition, OLGspecific gene expression abnormalities in animals can significantly influence neurotransmission, signal conduction, behavior, and neuronal morphology in ways that resemble some of the abnormalities noted in SZ (Benes et al, 1986; Rajkowska et al, 1998; Selemon et al, 1998; Roy et al, 2007). Finally, there is an apparent temporal relationship between myelination and the onset of SZ. Myelination in the frontal and temporal lobes, brain regions consistently implicated in the pathophysiology of SZ, occurs during late adolescence to early adulthood corresponding 
closely to the peak incidence of SZ onset (Huttenlocher, 1979; Terry et al, 1987; Benes, 1989; Benes et al, 1994; Goldman-Rakic and Selemon, 1997; Giedd et al, 1999). Thus, myelin gene expression abnormalities may have consequences for chemo- and cyto-architectural organizations that are consistent not only with some of the most robust neurobiological findings in SZ, but also with the disconnectivity hypothesis in SZ (Friston and Frith, 1995; Weinberger and Lipska, 1995).

Neuropathological studies in SZ have identified abnormalities in portions of the limbic system and its associated circuits (prefrontal cortex, cingulate, temporal gyri, and hippocampus) that are thought to subserve many of the aberrant behavioral and psychotic symptoms of SZ (Stevens, 1973; Torrey and Peterson, 1974; Kovelman and Scheibel, 1984; Barta et al, 1990; Rajkowska et al, 1998; Selemon et al, 1998; Selemon and Goldman-Rakic, 1999; Benes, 1999; Goldman-Rakic, 1999; Lim et al, 1999; Harrison, 1999; Weinberger, 1999; Haroutunian and Davis, 2000; Tamminga et al, 2000; Benes et al, 2001; MeyerLindenberg et al, 2001; Selemon and Rajkowska, 2003). These observations of multi-regional abnormalities have not been limited to neurons, as morphometric studies have shown reductions in glial cell densities in the anterior cingulate cortex (Cotter et al, 2001; Stark et al, 2004) as well as layer-specific reductions of glia in the dorsolateral prefrontal cortex of persons with SZ (Rajkowska et al, 2002; Hof et al, 2003). Adult myelinating OLGs are terminally differentiated postmitotic glial cells generated during early development from multipotent glial progenitor cells (OPC) (Liu et al, 2002). Evidence for the involvement of OLGs and myelin in the pathophysiology of SZ has come from analysis of postmortem tissue from persons with SZ using protein (Flynn et al, 2003; Dracheva et al, 2006) and gene expression studies (Hakak et al, 2001; Bahn and Jones, 2003; Tkachev et al, 2003; Aston et al, 2004; Iwamoto et al, 2005; Katsel et al, 2005a, b; Dracheva et al, 2006), light and electron microscopic studies (Miyakawa et al, 1972; Uranova et al, 2001, 2004; Vostrikov et al, 2007), and in vivo neuroimaging studies (Buchsbaum et al, 1998; Lim et al, 1999; Foong et al, 2000; Foong et al, 2001; Bartzokis et al, 2003). Recent gene expression studies have extended previous reports of myelin-associated gene expression deficits in the frontal cortex in SZ (Hakak et al, 2001; Bahn and Jones, 2003; Tkachev et al, 2003; Katsel et al, 2004, 2005b; Sugai et al, 2004; Iwamoto et al, 2005; Aberg et al, 2006a) to suggest that the cingulate cortex and the hippocampus are regions of special vulnerability (Katsel et al, 2005a, b; Dracheva et al, 2006). Although one recent post mortem gene and protein expression study failed to validate changes for four myelin-specific genes in DLPFC of persons with SZ (Mitkus et al, 2008). The human quaking gene (QKI), which encodes four major differentially spliced isoforms, is one of the OLG-associated genes whose expression is significantly affected in SZ (Haroutunian et al, 2006b; Aberg et al, 2006b). QKI has also been implicated in association studies (Aberg et al, 2006b). Current research has shown that downregulation of gene expression of the QKI transcript isoforms in quaking mice can hamper normal OLG differentiation (Larocque et al, 2005) and is suggestive of intrinsic unsuppressed cell cycle activity in OLGs of quaking mice.
In the canonical view of cell cycle regulation of somatic cells, mitogens, and/or growth factors elicit increases in the cyclins D-family of proteins and the activity of their associated kinases $(\mathrm{Cdk} 4 / 6)$ and sequester the Cip/Kip family of Cdk inhibitors (p21 ${ }^{\mathrm{Cip} 1}, \mathrm{p} 27^{\mathrm{Kip} 1}$, and $\mathrm{p} 57^{\mathrm{Kip} 2}$ ). Both proteins are believed to be the initial steps in the progression of cell cycle (G1/S phase transition). The activity of the CCND/Cdk4/6 complexes results in phosphorylation of the retinoblastoma (pRb, p107, and p130) family of 'pocket' proteins. Dephosphorylated pRb acts as a suppressor of cell cycle progression. Phosphorylation of $\mathrm{pRb}$, mediated by serine/threonine cyclin-dependent kinases, relieves this proliferation suppression activity and liberates E2F transcription factors. In turn, E2Fs initiate transcription of cell cycle proteins including cyclin $\mathrm{E}$ (CCNE) (Geng et al, 1996; Lundberg and Weinberg, 1998). The resulting CCNE/Cdk2 complex accumulation finalizes the $\mathrm{G} 1$ to $\mathrm{S}$ phase transition by complete inactivation of $\mathrm{pRb}$ through its phosphorylation (see cartoon in Figure 7) and coordinates histone synthesis for chromosomal DNA replication (Lundberg and Weinberg, 1998). QKI isoforms 6 and 7 intervene with progenitor cell proliferation by binding and increasing the stability of $\mathrm{p} 27^{\mathrm{Kip} 1} \mathrm{mRNA}$, which results in a rise of the $\mathrm{p} 27^{\mathrm{Kip} 1}$ protein believed to be a critical step in ensuring cell cycle arrest and subsequent differentiation into mature OLGs (Larocque et al, 2005). The other two Cdk inhibitors, $\mathrm{p} 21^{\mathrm{Cip} 1}$ and $\mathrm{p} 57^{\mathrm{Kip} 2}$ also play important roles in OLG differentiation. $\mathrm{p} 57^{\mathrm{Kip} 2}$ is an important component of the intrinsic molecular timer that regulates the number of divisions in OPC before the onset of differentiation. $\mathrm{p} 21^{\mathrm{Cip} 1}$ is necessary for OLG differentiation, but not necessarily for cell cycle arrest (Dugas et al, 2007).

We hypothesized that the widespread OLGs/myelin abnormalities observed in SZ may be due to events associated with the proliferation and differentiation of OLGs. This hypothesis is supported in part by the in situ and genetic evidence for the involvement of QKI in SZ. In the studies described here, we have focused on canonical cell cycle pathways by analyzing postmortem gene expression profiles in the ACG of persons with SZ and control subjects using Affymetrix's GeneChip ${ }^{\circledR}$ based microarray technology. We have validated the microarray findings by qPCR and protein analysis in independent samples. In addition, we have found that OLG-related cell cycle abnormalities may underlie the wide spread myelin deficits in some animal models with OLG-specific mutant genes providing further insights into the potential neurobiological mechanisms of OLG-associated deficits in SZ.

\section{MATERIALS AND METHODS}

\section{Sample Information and Preparation of Total RNA}

Brain tissue specimens were derived from the Brain Bank of the Department of Psychiatry of the Mount Sinai School of Medicine (New York, NY)/JJ Peters VA Medical Center (Bronx, NY). The precise tissue handling procedures have been described in detail (Haroutunian et al, 1998, 1999, 2006a, 2007; Davis et al, 1999). Controls were derived from nursing home residents who, on extensive medical chart review and care-giver interview, evidenced no neurological or neuropsychiatric diseases and died of natural causes 
(myocardial infarction, various nonbrain nonhepatic cancers, and congestive heart failure). All brain specimens were examined in detail by board certified neuropathologists using standardized procedures (Mirra et al, 1991). Specimens from any SZ or control cases that evidenced any discernable neuropathology were excluded from study (Purohit et al, 1998). None of the cases or controls had any history of licit or illicit drug abuse (tobacco use excepted).

Fourteen cerebral cortical regions (BAs: $8,10,44,46,4$, $23 / 31,24 / 32,20,21,22,36 / 28,38,7,17)$ and the hippocampus were dissected from flash frozen coronal sections, pulverized at $-80^{\circ} \mathrm{C}$ and aliquoted. Anterior cingulate (ACG, BA: 24/32) were dissected at the level of the genu of the corpus callosum. Aliquots $(50 \mathrm{mg})$ from each region were used for microarray gene expression analysis. Total RNA isolation and preparation for the microarrays were as described previously (Katsel et al, 2005a,b). Similarly prepared aliquots from the ACG and the white matter underlying the ACG were used in QPCR and western blot analyses (Dracheva et al, 2006; Haroutunian et al, 2006b).

All subjects died of natural causes with no history of licit or illicit drug abuse or neurological disease. Patients were diagnosed antemortem according to the Diagnostic and Statistical Manual of Mental Disorders, Fourth Edition criteria as described (Dracheva et al, 2005). Control (CNT) subjects (nursing home residents) with no evidence of neurological or neuropsychiatric diseases were matched with SZ subjects by age, postmortem interval (PMI), and brain $\mathrm{pH}$ (Table 1). Diagnostic and postmortem consent procedures were approved by the institutional review boards of Mount Sinai, Bronx VA, and Pilgrim Psychiatric Center.

A larger and independent set of brain tissue specimens from anterior cingulate (ACG, BA: 24/32 - at the level of the genu of the corpus callosum) was used for the qPCR experiments (Table 1). Mean RNA integrity numbers for control samples were $7.22 \pm 0.99$ and $7.16 \pm 1.34$ for SZ group. Ten of these subjects with SZ had been free of anti-psychotic medication for 4 weeks or more prior to death (Table 1). The half-life of haloperidol in the brain of chronically treated subjects is estimated to be about 6.8 days (Kornhuber et al, 1999). Therefore, after four or more half-lives of haloperidol, the brains of these subjects should have retained only a residual amount of the drug. Specimens from these cases were used in subgroup analyses to determine the effects of anti-psychotic medication.

\section{Animal Maintenance and Samples}

Brains of quaking- $q k^{e 5}$ homozygous mice were gifts of $\mathrm{Dr}$ Monica J Justice (Baylor College of Medicine, Houston, TX). The $q k^{e 5}$ mutation was induced on 101/R1 DNA after treatment with $N$-ethyl- $N$-nitrosourea and maintained as described previously (Noveroske et al, 2005). The molecular defect in the $q k^{e 5}$ allele is not known, but protein expression studies have shown decreased expression QKI-5 and lack of QKI-6 and -7 isoforms in postnatal OLGs (Noveroske et al, 2005). Myelin-associated glycoprotein (MAG) null mutant mice (Mag ${ }^{\text {tmlRod }}$ strain, Jackson Laboratory, Bar Harbor, ME) were maintained by sibling mating.

Genotypes were distinguished by PCR using conditions as outlined in the Jackson Laboratory protocol. Two to threemonth-old $q k^{e 5}$ mice with corresponding background wild type ( $N=4$ /group) and 6-12 month old MAG null mice with corresponding background wild type ( $N=8$ /group) were used in the study. Mice were killed by decapitation and the brains were removed and immediately dissected. Each brain was divided midsagitally. The left halves of the brains were stored at $-80^{\circ} \mathrm{C}$. The right halves were dissected fresh. Dissections included the frontal cortex gray matter (from the frontal pole to the beginning of the parietal cortex (bregma -1.8 (Franklin and Paxinos, 1997)), the corpus callosum underlying the dissected frontal cortical gray matter, and the hippocampus. The border of the frontal cortex and the parietal cortex was identified as the coronal block where the middle cerebral artery bifurcates from the internal carotid artery (Zeman and Innes, 1963) and the dissections were limited to the cortical region dorsal to the rhinal fissure. Procedures for total RNA isolation and cDNA preparation for qPCR have been described previously (Dracheva et al, 2001).

\section{Microarray Procedure and Data Analysis}

Microarray analysis was performed using Affymetrix (Santa Clara, CA) HG-U133AB GeneChip ${ }^{\mathbb{R}}$ set as described in the standard protocol outlined in the GeneChip ${ }^{\circledR}$ Expression Analysis Technical Manual (Affymetrix Inc., Santa Clara, CA) and reported previously (Katsel et al, 2005a, b; Haroutunian et al, 2007). Data were normalized using MAS 5.0 algorithms and analyzed using the $\mathrm{GX}^{\mathrm{TM}}$ Explorer v.3.0 (Gene Logic Inc., Gaithersburg, MD) tools (expression, comparative, and contrast analysis) as described previously (Katsel et al, 2005a, b, c). To reduce false discovery (Type I error), error rate gene expression change was considered to be significantly altered if the change in expression met the

Table I Characteristics of the Sample Groups Used in Microarray, qPCR and Protein Studies of ACG

\begin{tabular}{lcccccc}
\hline Characteristics & Control (array) & SZ (array) & Control (qPCR) & SZ (qPCR) & Control (western's) & SZ (western's) \\
\hline Patient number & 19 & 16 & 34 & 45 & 12 & 12 \\
Sex (M/F) & $8 / I 1$ & $13 / 3$ & $20 / 17$ & $19 / 26$ & $7 / 5$ & $7 / 5$ \\
Age (years) & $80.5 \pm 12.27$ & $74.3 \pm 11.6$ & $79.38 \pm 12.24$ & $76.48 \pm 10.68$ & $74.7 \pm 9.66$ & $81.2 \pm 9.66$ \\
Brain pH & $6.51 \pm 0.26$ & $6.46 \pm 0.23$ & $6.49 \pm 0.25$ & $6.47 \pm 0.28$ & $6.52 \pm 0.30$ & $742 \pm 462$ \\
PMl (min) & $462 \pm 392$ & $522 \pm 423$ & $532 \pm 434$ & $826 \pm 440$ & $852 \pm 322$ \\
\hline
\end{tabular}

Data are expressed as a mean $\pm \mathrm{SD}$. 
relatively stringent criteria of $p<0.05$ relative to the expression level in the control group; fold change $\geqslant 1.7$, present calls $\geqslant 80 \%$. To validate the results obtained by MAS 5.0 analysis the raw microarray data from $2147 \mathrm{HG}-\mathrm{U} 133 \mathrm{~A}$ and B individual chips were transformed and analyzed using GeneSpring GX 7.3.1 (Agilent Technologies/Silicon Genetics, Santa Clara, CA). Raw data were prenormalized with Robust Multi-Chip Average (RMA) (Bolstad et al, 2003; Irizarry et al, 2003) with subsequent log transformation, normalization to the 50th percentile of all values per chip and median-centred per gene using GeneSpring normalization. Statistical comparisons were made using GeneSpring's Cross Gene Error Model (CGEM), based on the deviation from 1.0 algorithm. To minimize the false positive/ negative error rate in these GeneSpring/RMA/CGEM analyses, we used a combination of confidence $(p \leqslant 0.05)$ and fold change $(\geqslant 1.6)$ with Benjamini and Hochberg multiple testing corrections (Benjamini and Hochberg, 1995). Genes accepted for subsequent validation by $\mathrm{GPCR}$ were those that met the high stringency criteria by both MAS 5.0- and RMA-based normalization of microarray analyses.

\section{Ingenuity Pathway Analysis}

A dataset containing identifiers for the genes expressed (presence $\geqslant 80 \%)$ in the samples from the ACG $(\sim 3580$ transcripts) and corresponding $p$-values obtained from the comparison analysis (MAS5.0 normalization, GX ${ }^{\mathrm{TM}}$ Explorer v.3.0, Gene Logic Inc.) between control and SZ samples was uploaded into the application. Differentially regulated genes $(p \leqslant 0.05)$ were overlaid onto a global molecular network in the Ingenuity Pathways Knowledge Base (Ingenuity ${ }^{\circledR}$ Systems, www.ingenuity.com) to identify biological functions and canonical pathways. Ingenuity pathway analysis algorithmically generates networks of genes based on their connectivity. Fischer's exact test was used to calculate a $p$-value determining the probability that each biological function assigned to that dataset, or the association between genes in the dataset and the canonical pathway, was not due to chance alone. Significant $(p s<0.05)$ canonical pathways were additionally ranked according to the ratios between the numbers of genes from the dataset that mapped to the pathway to the total numbers of genes in the canonical pathway. The scores for the networks were calculated based on the number of network eligible genes and the size of the network to approximate how relevant any particular network was to the total list of eligible genes. Only the top five scoring networks are shown (Table 3).

\section{RT-qPCR}

The mRNA levels of myelin and cell cycle genes, which met selection criteria of both MAS 5.0- and RMA-based microarray analysis were measured by qPCR in a larger independent cohort (Table 1) using TaqMan ${ }^{\circledR}$ MGB probes and primer sets (Applied Biosystems, Foster City, CA). CDK inhibitor-p2 $1^{\text {Cip } 1}$, which did not show significant changes in the microarrays, was additionally included for qPCR experiments to test the possibility that all three members of Cip/Kip family of CDK inhibitors are affected in the ACG of persons with SZ. TaqMan ${ }^{\circledR}$ probe ID's for selected cell cycle genes and normalization controls are listed in Table 2.
For relative quantification of mRNA expression, geometric means were calculated using the comparative $2^{-\Delta \Delta} C_{t}$ method described previously (Dracheva et al, 2005). Three housekeeping genes (GUSB, PPIA, and PGK1) were selected for human postmortem studies in ACG after comparison of six different endogenous controls and their analysis for expression stability using geNorm (http:// medgen.ugent.be/ jvdesomp/genorm/). Two housekeeping genes (GAPDH and PPIA) were used as the endogenous references in the mouse studies. Microglial-specific marker-CD68 was not expressed abundantly enough in the brain samples examined for reliable analysis.

\section{Quantitative Western Blotting}

Protein abundance was measured in the ACG and white matter (underlying the ACG) from SZ and CNT subjects ( $N=12$ /group) previously selected for microarray analysis (Table 1) and in brain samples from qke5 and wild-type mice ( $N=4$ /group) using western blotting. To evaluate the stability of the cyclin D/Cdk complex-dependent phosphorylated retinoblastoma protein $(\mathrm{pRB})$ at different postmortem intervals (Figure 3), mouse brain tissue specimens $(\sim 15 \mathrm{mg})$ were dissected from the same animals and were immediately frozen or stored for either 6 or $20 \mathrm{~h}$ at room temperature before homogenization and western blotting.

Tissue specimens ( $\sim 50 \mathrm{mg}$-human, $\sim 15 \mathrm{mg}$-mouse $)$ were homogenized in Urea/Tris solution: $50 \mathrm{mM}$ Tris/ $\mathrm{HCl}$ $\mathrm{pH} 7.4 ; 6 \mathrm{M}$ Urea; $2 \%$ CHAPS containing $1 \mathrm{mM}$ PMSF and cocktails of proteinase/phosphatase inhibitors (Pierce Biotech Inc., Rockford, IL). Total protein concentration in the tissue homogenates was determined with a CBQCA Quantitation Kit (Molecular Probes Inc., Eugene, OR). Aliquot samples of $15 \mu \mathrm{g}$ of total protein in triplicates were loaded onto precast $4-12 \%$ Tris-glycine gel (Invitrogen, Carlsbad, CA) under reduced conditions. A 'standard calibrator' (a mix of small aliquots of tissue from all samples) was used as a calibrator between the gels and run on each gel in triplicate. Electrophoresis, blotting, immunostaining and detection (ECL Plus-GE Healthcare, Piscataway, NJ) were performed under standard conditions. Mouse monoclonal antibodies: anti-human phosphorylated Ser608 pRB were from AbD/Serotec (Raleigh, NC); antimouse phosphorylated Ser807/811 pRB - from Cell Signaling Technology Inc., (Danvers, MA); anti-human dephosphorylated $\mathrm{pRb}$ - from BD PharMingen (Franklin Lakes, NJ); total pRB - from Santa Cruz Biotech Inc., (Santa Cruz, CA) and anti-GAPDH was from Biodesign International (Saco, ME). The linearity of the dose responses for the antibodies used was established in preliminary experiments. Film images were digitized on Alpha ChemImager ${ }^{\mathrm{TM}} 5500$ and quantitated with AlphaEaseFC software (Alpha Innotech Corp, San Leandro, CA). To account for gel to gel variability, the relative expression value of $\mathrm{ppRb}$ (Ser608) or ppRb (Ser807/811) in each sample was calculated as a ratio between the averaged intensities of the band in the experimental sample and in the 'standard-calibrator'. The relative abundance of GAPDH and total $\mathrm{pRb}$ protein was determined in the same manner as for ppRb. Finally, mean values of the ratios of $p p R b / G A P D H$ and $p p R b / t o t a l$ $\mathrm{pRb}$ were normalized to the amount of total protein. 
Table 2 TaqMan Gene Expression Assays Used in the Study

\begin{tabular}{|c|c|c|c|c|c|}
\hline Gene symbol & Species & AB Assay ID & NCBI accession no & Exon boundary & Location \\
\hline CCNDI & Homo sapiens & Hs00277039_ml & NM_053056.I & Exon 2 | Exon3 & 625 \\
\hline CCND2 & Homo sapiens & Hs00I53380_m l & NM_001759.2 & Exon3 | Exon4 & 845 \\
\hline CCNE2 & Homo sapiens & $\mathrm{Hs00I80319 \_ ml}$ & NM_057749.I & Exon 7 | Exon 8 & 705 \\
\hline CDKNIA (p2 $\left.\left.\right|^{\mathrm{Cip} \mid}\right)$ & Homo sapiens & Hs00355782_ml & NM_078467.I & Exon 2 | Exon 3 & 680 \\
\hline CDKNIB (p27 Kipl) & Homo sapiens & Hs00I53277_ml & NM_004064.2 & Exon I | Exon2 & 945 \\
\hline GUSB & Homo sapiens & Hs99999908_ml & NM_000|8|.I & Exon $11 \mid$ Exon 12 & 1816 \\
\hline NPAT & Homo sapiens & Hs00I59638_ml & NM_0025 I9.I & Exonl0 | Exonll & 945 \\
\hline PGKI & Homo sapiens & Hs99999906_ml & NM_000291.2 & Exon 4 | Exon 5 & 494 \\
\hline PHB & Homo sapiens & Hs00855044_gl & NM_002634.2 & Exon 7 | Exon 7 & 1263 \\
\hline PPIA & Homo sapiens & Hs99999904_ml & NM_02 I I 30.3 & - & 435 \\
\hline CDKNIA (p2| $\left.\left.\right|^{\mathrm{Cipl}}\right)$ & Mus musculus & Mm00432448_ml & NM_007669.2 & Exon 2 | Exon 3 & 525 \\
\hline CDKNIB (p27 Kip। $)$ & Mus musculus & Mm00438I68_ml & UI0440.I & Exon 2 | Exon 3 & 819 \\
\hline CDKNIC (p57 $\left.7^{\text {Kip2}}\right)$ & Mus musculus & Mm00438I70_ml & NM_009876.2 & Exon 2 | Exon 3 & 1028 \\
\hline CNPI & Mus musculus & Mm0I306640_ml & NM_009923 & - & 759 \\
\hline GAPDH & Mus musculus & Mm999999|5_gl & NM_00 I00 I303.I & Exon 2 | Exon 3 & - \\
\hline MAG & Mus musculus & Mm00487538_ml & NM_0I0758 & Exon 5 I Exon 6 & 558 \\
\hline MBP & Mus musculus & Mm00521979_ml & NM_0I0777 & - & 436 \\
\hline PLPI & Mus musculus & Mm0I2972I0_ml & NM_0III 23 & Exon 2 | Exon 3 & 340 \\
\hline PPIA & Mus musculus & Mm02342429_gl & NM_008907.I & Exon 3 | Exon 4 & - \\
\hline QKI & Mus musculus & Mm0049899I_ml & NM_02|88| & Exon 4 | Exon 5 & 1190 \\
\hline
\end{tabular}

\section{Statistical Data Analysis}

Multiple statistical procedures were employed for different aspects of the study. Max $t$-scores (Budhraja et al, 2003; Mariani et al, 2003) for each individual transcript were calculated by contrast analysis of MAS5.0 normalized microarray data using GX ${ }^{\mathrm{TM}}$ Explorer v.3.0 (Gene Logic Inc., Gaithersburg, MD). $t$-scores were used as a standardized measure of gene expression change for each individual transcript across all of the analyzed brain regions as described previously (Katsel et al, 2005b, 2007). The calculation algorithm of $t$-scores takes into account variability across all studies brain regions. Accordingly genes with high magnitudes of changes and lower variability have higher $t$-scores than those with similar mean changes but high variability. Differences in expression between CNT and SZs in the ACG in the GeneSpring/RMA/CGEM analyses were examined using a one-way analysis of variance (ANOVA) with Benjamini and Hochberg multiple testing corrections (Benjamini and Hochberg, 1995).

Consistent with previously published procedures (Katsel et al, 2005b) categorizations by gene ontology (GO) was based on functional class scoring (FCS) (Pavlidis et al, $2002,2004)$ which examines the statistical distribution of individual gene scores ( $t$-scores) for each gene among all genes in the GO class. FCS was carried out by the ErmineJ software (ver. 2.1.12, University of British Columbia, Vancouver) on the complete list of transcripts with detection $p$-values $\leqslant 0.06$
(13 472 transcripts) without any additional selection criteria. GO terms were only considered if between eight to 150 unique members were assayed for that class.

Correlations were performed based on cell cycle gene expression changes from the microarray data to determine their association with any particular neural cell population. For correlations, individual intensity values (MAS5.0 normalized) of five cell cycle genes (cyclins D1, D2, E2, and CDK inhibitors, p27 ${ }^{\text {Kip } 1}$ and p57 $7^{\text {Kip2 }}$ ), two myelin/ OLG-specific markers (PMP22 and SOX10), one astrocyte (GFAP) and two neuronal markers (MAP2 and NEFL) were selected (Table 5) from ACG and analyzed. A two-tailed Student's $t$-test was used to compare relative mRNA expression of cell cycle and myelin/OLG-specific genes in qPCR experiments and relative abundance of $\mathrm{ppRb}$ protein in human and animal models experiments. Student's $t$-test and correlation analyses were performed using Statistica (release 6.0).

\section{RESULTS}

\section{Canonical Cell Cycle Pathways Affected in SZ as Revealed by Microarray Analysis}

We have shown in previous studies (Katsel et al, 2005b; Haroutunian et al, 2006b) that the ACG is one of the four regions (BAs 23/31,24/32, 21, and HIPP) where alterations in the expression of OLG/myelin genes are most prevalent 
in SZ. In those studies, multiple gene ontology categories, related to myelination/nerve ensheathment, contributed to nearly half of the top 20 Gene Ontology categories in the cingulate gyri of persons with SZ (Katsel et al, 2005b). Ingenuity Pathway Analysis was used to reanalyze those results and determine what signaling pathways were affected in the ACG of persons with SZ. Cell cycle or cell cycle-related categories represented by highly significant $p$-values (Fischer's test) were at the top of the list of gene networks, molecular/cellular functions and potential disorders that were affected in the ACG in SZ (Table 3). Cell cycle-related function appeared to be associated with three of the top five gene networks. Additionally, cell cycle canonical pathways, including G1/S checkpoint regulation and G2/M DNA damage checkpoint regulation were among the significantly affected canonical pathways in the ACG of persons with SZ. We additionally analyzed differentially expressed genes in the ACG by the FCS method to test whether cell cycle-related categories maintain significance after multiple testing (200 000 iterations) against randomly generated gene classes of the same size. The $p$-values of categories related to cell cycle (mitosis, G1/S phase, and M phase of mitotic cell cycle) remained highly significant $(p<0.001)$.

Microarray data (contrast analysis $t$-scores (Katsel et al, 2005b)) from both ACG and from all of the brain regions examined, implicated two members of the cyclins D family, CCND1 and CCND2, the main activators of the G1 phase entry. These two genes were among the top 10 cell cycle genes upregulated in SZ (Table 4). On the other hand, genes that are critical to cell cycle inhibition, p2 $7^{\text {Kip1, }}$ p57 $7^{\text {Kip2 }}$-inhibitors of the CCND/CDK4,6 complexes - were downregulated, suggesting activation of the cell cycle and transition from G1 to $\mathrm{S}$ phases (Table 4). Upregulation of the genes associated with the $S$ phase of the cell cycle, ORC5 L, MCM3, and CDK6 (Table 4), suggests further that DNA replication may also be in an active state in SZ. Overall, detected cell cycle genes (Table 4) remained within the top $15 \%$ of all differentially expressed genes across all of the 15 brain regions, or within the top 5\% of differentially expressed genes in ACG.

RMA-CGEM methods using ANOVA with Benjamini Hochberg multiple testing corrections confirmed the five differentially expressed genes in SZ cell cycle $\left(\mathrm{p} 27^{\mathrm{Kip} 1}, \mathrm{p} 57^{\mathrm{Kip} 2}, \mathrm{CCND} 1, \mathrm{CCND} 2, \mathrm{CCNE} 2, \mathrm{ps}<0.05\right)$ that met MAS5.0 stringency criteria (Table 4). In addition, RMA-CGEM analysis using ANOVA with Benjamini Hochberg multiple testing corrections revealed the differential expression of four other genes integral to G1/S phase checkpoint progression. These included the upregulated transcription factor DP1 (TFDP1, $p=0.0004$ ), the nuclear protein ataxia-telangiectasia locus (NPAT, $p=0.002$ ), the downregulated retinoblastoma like $2(\mathrm{RBL} 2, p=0.0001)$ and prohibitin (PHB, $p=0.009$ ).

\section{Majority of Complex Correlations Between Gene Expression of Cell Cycle Proteins and Neuronal or Glial Markers in Controls are Absent in SZ}

Correlations between mRNA levels of cell cycle genes and established cell-specific markers/genes were performed to determine whether the expression of the identified cell cycle
Table 3 Summary of Ingenuity Pathway Analysis

Top networks

\begin{tabular}{llc}
\hline Number & Associated network functions & Score \\
\hline 1 & $\begin{array}{l}\text { Cellular development, cellular growth } \\
\text { and proliferation, nervous system } \\
\text { development }\end{array}$ & 39 \\
& $\begin{array}{l}\text { RNA post-transcriptional modification, } \\
\text { gene expression, molecular transport } \\
\text { Cell cycle, embryonic development, }\end{array}$ & 37 \\
tissue development \\
Cancer, reproductive system disease, \\
renal, and urological disease \\
Gene expression, viral function, \\
cellular compromise
\end{tabular}

Top functions

\begin{tabular}{lcc}
\hline $\begin{array}{l}\text { Disease and } \\
\text { disorders }\end{array}$ & $\boldsymbol{p}$-value & $\begin{array}{c}\text { Number of } \\
\text { molecules }\end{array}$ \\
\hline Cancer & $0.0007-0.04$ & 54 \\
Neurological disease & $0.001-0.04$ & 19
\end{tabular}

\section{Molecular and \\ cellular functions}

\begin{tabular}{lll}
\hline Cell cycle & $0.0004-0.04$ & 49 \\
Cell to cell signaling & $0.0007-0.04$ & 43 \\
and interaction & & 52 \\
Lipid metabolism & $0.002-0.04$ & 62 \\
Molecular transport & $0.002-0.04$ & 81 \\
Small molecule & $0.002-0.04$ & \\
biochemistry & & \\
\hline
\end{tabular}

genes was associated with any particular neural cell population. Correlation coefficients between five cell cycle genes, two myelin/OLG, two neuronal markers and one marker for astrocytes are shown (Table 5).

In controls, the RNA expression levels of the CDK inhibitors, $\mathrm{p} 27^{\mathrm{Kip} 1}$ and $\mathrm{p} 57^{\mathrm{Kip} 2}$ were positively correlated with each other and with cyclin E2, and were negatively correlated with cyclin D2 ( $p s<0.01)$. The glial and neuronal markers showed significant positive correlations within their cell type-specific groups and negative correlations between cell type-specific groups indicating marker specificity $(p s<0.05)$. When tested against cell-specific markers, most of the tested cell cycle genes demonstrated complex but predictable relationships with OLG, astrocytic, and neuronal markers. CDK inhibitors, p2 $7^{\mathrm{Kip} 1}, \mathrm{p} 57^{\mathrm{Kip} 2}$, and cyclins E2, and D1 exhibited positive correlations with OLGs markers $(p s<0.05)$, and negative correlations with neuronal markers $(p s<0.05)$. In contrast, CCND2 showed negative correlations with OLG markers, but positive correlations with the expression of genes encoding neuronal proteins $(p s<0.05)$. Additionally, the astrocyte marker, glial fibrillary acidic protein (GFAP), was positively correlated with $\mathrm{p} 57^{\mathrm{Kip} 2}$ and negatively correlated with CCND2 $(p s<0.05)$. The majority of these correlations remained 
Table 4 Differentially Expressed Cell Cycle Genes in 15 Brain Regions in SZ

\begin{tabular}{|c|c|c|}
\hline Gene name & Symbol & $t$-score \\
\hline \multicolumn{3}{|l|}{ Upregulated } \\
\hline Cyclin D2 & CCND2 & 4.69 \\
\hline $\begin{array}{l}\text { Origin recognition complex, } \\
\text { subunit } 5 \text {-like }\end{array}$ & ORC5L & 4.37 \\
\hline Histone deacetylase 8 & HDAC8 & 3.36 \\
\hline Transforming growth factor, $\beta 3$ & TGFB3 & 3.30 \\
\hline Cyclin DI & CCNDI & 3.18 \\
\hline MAD2 mitotic arrest deficient-like I & MAD2LI & 2.89 \\
\hline $\begin{array}{l}\text { SMAD, mothers against DPP } \\
\text { homolog } 3\end{array}$ & SMAD3 & 2.63 \\
\hline Cyclin-dependent kinase 6 & CDK6 & 1.62 \\
\hline \multicolumn{3}{|l|}{ Downregulated } \\
\hline $\begin{array}{l}\text { Growth arrest and DNA- } \\
\text { damage-inducible, } \beta\end{array}$ & GADD45B & -7.93 \\
\hline $\begin{array}{l}\text { Growth arrest and DNA- } \\
\text { damage-inducible, } \alpha\end{array}$ & GADD45A & -6.46 \\
\hline $\begin{array}{l}\text { Cyclin-dependent kinase inhibitor } \\
\text { IC }\left(\mathrm{p}^{5} 7^{\mathrm{Kip} 2}\right)\end{array}$ & CDKNIC & -5.55 \\
\hline $\begin{array}{l}\text { Cyclin-dependent kinase inhibitor } \\
\text { IB }\left(p 27^{\text {ip }}\right)\end{array}$ & CDKNIB & -4.95 \\
\hline $\begin{array}{l}\text { Budding uninhibited by } \\
\text { benzimidazoles } 3 \text { homolog (yeast) }\end{array}$ & BUB3 & -4.89 \\
\hline Proliferating cell nuclear antigen & PCNA & -4.83 \\
\hline Cell division cycle 14 homolog B & $\mathrm{CDCl} 4 \mathrm{~B}$ & -4.62 \\
\hline $\begin{array}{l}\text { Structural maintenance } \\
\text { of chromosomes |-like | }\end{array}$ & SMCILI & -4.21 \\
\hline Retinoblastoma protein I & $\mathrm{RB} \mid$ & -2.64 \\
\hline
\end{tabular}

The $t$-scores were calculated by contrast analysis (GX ${ }^{T M}$ Explorer v.3.0, Gene Logic Inc.) as described previously (Katsel et al, 2005a, b), Genes are arranged in descending order or magnitude of change.

significant even after Bonferroni correction for multiple tests of significance.

When the expression values for the same cell cycle genes and cell-specific marker/genes were compared in the SZ samples, only three cell cycle genes were significantly correlated with OLG markers ( $227^{\mathrm{Kip} 1}$ and p57 $7^{\mathrm{Kip} 2}$ were positively correlated and CCND2 was negatively correlated) $(p s<0.05)$, and one gene, $\mathrm{p} 27^{\mathrm{Kip} 1}$ was negatively correlated with the MAP2 neuronal marker $(r=-0.53 ; p=0.04)$. As for cell-specific marker/genes, the statistically significant negative correlations between neurons and glia observed in controls were entirely lost in SZ samples, suggesting disassociation of transcription profiles for the expression of the measured genes in neurons and glia in SZ. In contrast, CCND1 which did not exhibit significant correlations with the astrocyte marker, GFAP, in controls showed significant positive correlations with GFAP in SZ.

\section{Real-Time PCR Validation of Alterations in Gene Expression of Key G1/S Phase Checkpoint Proteins}

Ten cell cycle genes (Table 6) that met high stringency filtering conditions by the two different microarray normalization methods (MAS5.0 and RMA-CGEM) were selected from the list of differentially expressed genes in $\mathrm{SZ}$ for qPCR analysis in an independent and significantly larger sample of cases and controls from the ACG.

As shown in Figure 1 the expression of $\mathrm{p} 57^{\mathrm{Kip} 2}$ was lower in SZs and the relative expression of cyclin D1, TFDP1, and NPAT was higher in SZs relative to controls. Table 6 lists fold changes and significant values ( $t$-test) between relative expression of the 10 cell cycle genes in SZ and control samples from ACG. Together, fold change ratios and significant $p$-values indicated strong gene expression changes for CCND1, TFDP1, NPAT, and $\mathrm{p} 57^{\mathrm{Kip} 2}$ in ACG in SZ. Sample pH, PMI or age of the donors did not correlated significantly with gene expression levels, except for $\mathrm{p} 57^{\mathrm{Kip} 2}$ which showed negative correlation with PMI $(r=-0.43, p=0.001)$.

The qPCR showed that gene expression changes for four validated cell cycle genes (Figure 1 and Table 6) were even more pronounced in the subgroup of patients who had been free of anti-psychotic medication for 4 weeks or more prior to death $\left(\mathrm{SZ}_{\mathrm{OFF}}\right)$, as supported by the increased magnitude of the fold change ratios (Table 6). Non-affected cell cycle proteins-p21 ${ }^{\mathrm{Cip} 1}, \mathrm{p} 27^{\mathrm{Kip} 1}, \mathrm{CCND} 2, \mathrm{RBL} 2, \mathrm{CCNE} 2$, and PHB remained unchanged in the $\mathrm{SZ}_{\mathrm{OFF}}$ subgroup.

\section{Increased Phosphorylation of Retinoblastoma Protein in the White Matter and ACG in SZ and Quaking Mice}

Based on the multiple lines of evidence supporting abnormal OLG differentiation in quaking mice (Larocque et al, 2005) and possible unsuppressed cell cycle activity in OLGs, we assessed the possibility of increased phosphorylation of $\mathrm{pRb}$ in the white matter of quaking mice as compared to wild-type mice. As shown in Figure 2 phosphorylation of $\mathrm{pRb}$ at $\mathrm{S} 807 / 811$ was significantly increased $(p=0.002)$ in the white matter of quaking mice.

The relative abundance of ppRb (S807/811) at different postmortem intervals in mouse brain, reflecting stability of the cyclin D/Cdk complex-dependent phosphorylation of $\mathrm{pRb}$, is shown in Figure 3. The ppRb band showed an initial $\sim 27 \%$ decrease in relative intensity values during the first $6 \mathrm{~h}$ postmortem at room temperature, but remained constant thereafter for up to $20 \mathrm{~h}$ at room temperature. This observation suggests that postmortem interval should not profoundly impact or falsely inflate the levels of phosphorylated $\mathrm{pRb}$ in the closely matching human specimens.

Phosphorylation at the $\mathrm{S} 608$ of $\mathrm{pRb}$, distinctive for phosphorylation by either cyclin D1/CDK4 or cyclin A/ CDK2 complexes, but not by the cyclin E/CDK2 kinase complex (Zarkowska and Mittnacht, 1997), was significantly $(p=0.024)$ increased in the white matter and demonstrated a tendency to increase in the ACG gray matter of subjects with SZ relative to controls (Figure 4).

\section{Alterations in Gene Expression of Cell Cycle Proteins in Myelin Mutant Mice Models}

These studies sought to determine whether cell cycle gene expression changes accompany gene expression deficits in OLG/myelin genes in mouse models systems that are reminiscent of those in ACG of subjects with SZ. Gene 
Table 5 Correlation coefficients among the mRNA levels of the cell cycle genes and cell-specific markers in the ACG

\begin{tabular}{|c|c|c|c|c|c|c|c|c|c|c|}
\hline & $\begin{array}{c}p 27^{K i p 1} \\
C D K N 1 B\end{array}$ & $\begin{array}{c}p 57^{K i p 2} \\
C D K N 1 C\end{array}$ & Cyclin D1 & Cyclin D2 & Cyclin E2 & $\begin{array}{c}\text { MYELIN } \\
\text { SOX10 }\end{array}$ & $\begin{array}{c}\text { MYELIN } \\
\text { PMP22 }\end{array}$ & $\begin{array}{c}\text { ASTRO } \\
\text { GFAP }\end{array}$ & $\begin{array}{c}\text { NEURON } \\
\text { MAP2 }\end{array}$ & $\begin{array}{c}\text { NEURON } \\
\text { NEFL }\end{array}$ \\
\hline$p 27^{K i p 1}$ & & 0.2744 & 0.1904 & -0.0660 & 0.6148 & 0.6567 & 0.4478 & -0.1758 & -0.5335 & 0.3295 \\
\hline CDKN1B & & $p=0.322$ & $p=0.497$ & $p=0.815$ & $p=0.015$ & $p=0.008$ & $p=0.094$ & $p=0.531$ & $p=0.041$ & $p=0.230$ \\
\hline$p 57^{K i p 2}$ & 0.7542 & & 0.0638 & -0.3525 & 0.2140 & 0.6485 & 0.6001 & 0.1411 & -0.1013 & -0.0945 \\
\hline CDKN1C & $p=0.000$ & & $p=0.821$ & $p=0.198$ & $p=0.444$ & $p=0.009$ & $p=0.018$ & $p=0.616$ & $p=0.719$ & $p=0.738$ \\
\hline \multirow[t]{2}{*}{ Cyclin D1 } & 0.3421 & 0.4643 & & -0.3201 & 0.4633 & 0.1302 & 0.1761 & 0.6606 & -0.2271 & 0.4734 \\
\hline & $p=0.179$ & $p=0.060$ & & $p=0.245$ & $p=0.082$ & $p=0.644$ & $p=0.530$ & $p=0.007$ & $p=0.416$ & $p=0.075$ \\
\hline \multirow[t]{2}{*}{ Cyclin D2 } & -0.6543 & -0.6582 & -0.1659 & & -0.2667 & -0.4554 & -0.5278 & -0.2779 & -0.0089 & -0.0621 \\
\hline & $p=0.004$ & $p=0.004$ & $p=0.525$ & & $p=0.337$ & $p=0.088$ & $p=0.043$ & $p=0.316$ & $p=0.975$ & $p=0.826$ \\
\hline \multirow[t]{2}{*}{ Cyclin E2 } & 0.6117 & 0.4605 & 0.3521 & -0.5655 & & 0.3948 & 0.1418 & -0.0277 & -0.1262 & 0.3605 \\
\hline & $p=0.009$ & $p=0.063$ & $p=0.166$ & $p=0.018$ & & $p=0.145$ & $p=0.614$ & $p=0.922$ & $p=0.654$ & $p=0.187$ \\
\hline MYELIN & 0.6166 & 0.8250 & 0.4919 & -0.5614 & 0.5863 & & 0.9061 & 0.2235 & -0.4238 & -0.1485 \\
\hline sox10 & $p=0.008$ & $p=0.000$ & $p=0.045$ & $p=0.019$ & $p=0.013$ & & $p=0.000$ & $p=0.423$ & $p=0.115$ & $p=0.597$ \\
\hline MYELIN & 0.6613 & 0.7304 & 0.1640 & -0.7098 & 0.5680 & 0.5823 & & 0.4170 & -0.4443 & -0.1909 \\
\hline PMP22 & $p=0.004$ & $p=0.001$ & $p=0.529$ & $p=0.001$ & $p=0.017$ & $p=0.014$ & & $p=0.122$ & $p=0.097$ & $p=0.496$ \\
\hline ASTRO & 0.3552 & 0.4939 & 0.4683 & -0.5539 & 0.4168 & 0.5337 & 0.6369 & & -0.2696 & 0.4813 \\
\hline GFAP & $p=0.162$ & $p=0.044$ & $p=0.058$ & $p=0.021$ & $p=0.096$ & $p=0.027$ & $p=0.006$ & & $p=0.331$ & $p=0.069$ \\
\hline NEURON & -0.6287 & -0.7293 & -0.6069 & 0.5402 & -0.4985 & -0.7885 & -0.5383 & -0.6784 & & -0.1792 \\
\hline MAP2 & $p=0.007$ & $p=0.001$ & $p=0.010$ & $p=0.025$ & $p=0.042$ & $p=0.000$ & $p=0.026$ & $p=0.003$ & & $p=0.523$ \\
\hline NEURON & -0.4560 & -0.6363 & -0.4294 & 0.6462 & -0.5930 & -0.6807 & -0.6562 & -0.5990 & 0.6059 & \\
\hline NEFL & $p=0.066$ & $p=0.006$ & $p=0.085$ & $p=0.005$ & $p=0.012$ & $p=0.003$ & $p=0.004$ & $p=0.011$ & $p=0.010$ & \\
\hline
\end{tabular}

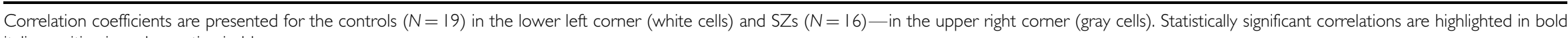
italic: positive-in red; negative-in blue. 
Table 6 Expression analysis of the cell cycle genes in ACG

\begin{tabular}{|c|c|c|c|c|}
\hline Gene symbol & $\mathbf{S Z}$ total $\mathrm{FC}$ ratio & $\mathbf{S Z}_{\text {total }} P$-value & SZ OFF FC ratio & SZ OFF $P$-value \\
\hline CCNDI & 1.5 & 0.033 & 1.92 & 0.005 \\
\hline NPAT & 1.2 & 0.005 & 1.34 & 0.003 \\
\hline TFDP I & 1.35 & 0.011 & 1.5 & 0.01 \\
\hline$p 27^{\text {Kip } 1}$ & 1.18 & ns & 1.07 & ns \\
\hline CCNE2 & 1.03 & ns & 1.01 & ns \\
\hline PHB & -1.12 & ns & -1.17 & ns \\
\hline p2 $\left.\right|^{\text {Cipl }}$ & -1.11 & ns & 1.36 & ns \\
\hline p5 $7^{\text {Kip2 }}$ & -1.47 & 0.039 & -1.73 & 0.031 \\
\hline
\end{tabular}

Tissue samples from the ACG of controls $(N=34)$ and $S Z(N=45)$ were analyzed by qPCR. FC Ratio — fold change ratios represent the ratio of geometric means for each gene to the three housekeeping genes in $\mathrm{SZ} /$ control $(+)$ and in control/SZ (-) values. $\mathrm{SZ}$ total -all the subjects with $\mathrm{SZ}$. SZ $\mathrm{SFF}(\mathrm{N}=10)$-subjects with $\mathrm{SZ}$, whose neuroleptic treatment was discontinued for at least 4 weeks prior to death. Differentially changed genes $(p<0.05)$ are highlighted in bold. ns-non-significant.

\section{G1/S phase transition: CDK Inhibitors and cyclins}
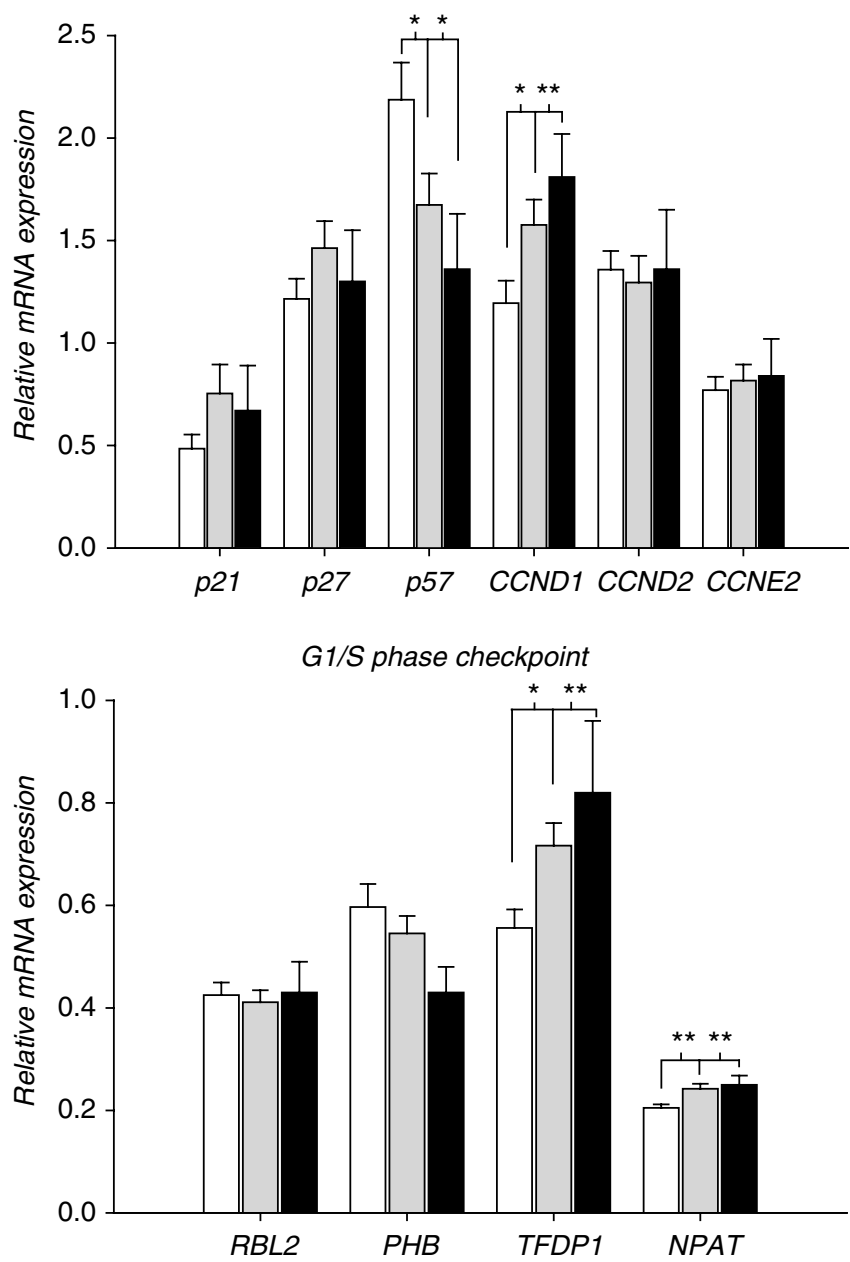

Figure I Relative mRNA expression of the GI/S phase checkpoint genes in the anterior cingulate gyrus (BA 24/32) of persons with SZ measured by qPCR. Comparison subjects - white bars $(N=34)$; $S Z$ subjects - gray filled bars $(N=45)$ and $\mathrm{SZ}_{\mathrm{OFF}}$ subjects whose neuroleptic treatment was discontinued for at least 4 weeks prior to death — black bars $(N=10)$. Data is expressed as geometric means \pm SEM of individual expression values normalized to the three housekeeping genes: GUSB, PPIA, and PGKI as described in Methods.* $p s \leqslant 0.05 ; * * * \leqslant 0.01$.

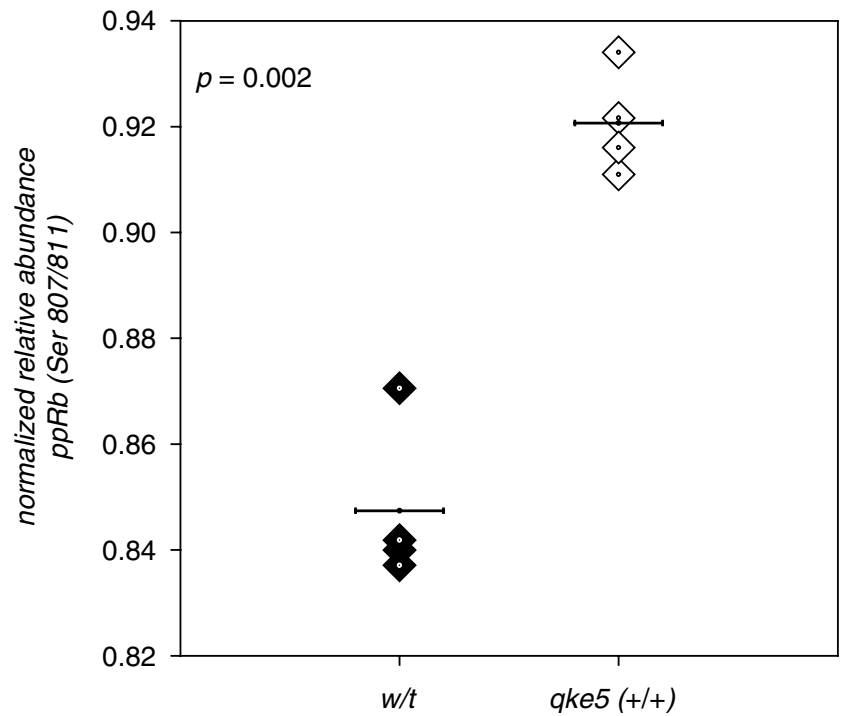

Figure 2 Relative abundance of phosphorylated (S807/8II) retinoblastoma protein in the white matter of $q k^{\mathrm{e} 5}$ mice. Expression of ppRb (S807/ $8 \mathrm{I}$ ) was measured by western blot. Data expressed as means of $\mathrm{ppRb}$ $(S 807 / 8$ II) ODs normalized to total $\mathrm{pRb} / \mathrm{GAPDH}$ and total protein ( $N=4 /$ group). Plot displays the group means (horizontal line).

expression of a panel of OLG/myelin genes, including MAG, MBP, PLP1, CNP, QKI (the pan probe for all QKI isoform) and a panel of five cell cycle genes including $\mathrm{p} 21^{\mathrm{Cip} 1}$, p2 $7^{\text {Kip1 }}$, p5 $7^{\text {Kip2 }}$, cyclin D1, and D2 was measured by qPCR in the white matter and hippocampus of quaking mice (Figure 5) to determine whether cell cycle gene expression changes accompany gene expression deficits of the OLG/ myelin genes. All measured OLG/myelin genes showed significant decreases $(p s \leqslant 0.05)$ in the white matter and hippocampus of quaking mice as compared with controls (MAG, CNP, PLP1, and MBP (Figure 5a and b; inserts) and QKI (Figure $5 a$ and $b$ ). The gene expression of cyclin D1 and D2 and two CDK inhibitors (p21 ${ }^{\text {Cip1 } 1}$ and $\mathrm{p} 27^{\mathrm{Kip} 1}$ ) was decreased $(p s<0.05)$ in both white matter and hippocampus and the expression levels of $\mathrm{p} 57^{\mathrm{Kip} 2}$ and cyclin D2 were decreased $(p s<0.05)$ in the white matter of quaking mice (Figure 5, upper panel). 
To address the question of whether deficiency of gene expression of a protein important for myelin structural integrity can affect gene expression abnormalities of the canonical cell cycle proteins, gene expression of the same panel of OLG/myelin and cell cycle was measured by qPCR in MAG null mutant mice (Figure 6). In contrast to quaking mice, MAG null mice evidenced significant $(p s \leqslant 0.05)$ increases in gene expression in the majority of the OLG/myelin genes (with the exception of MAG) in both the hippocampus and the white matter (MAG, CNP, PLP1, and MBP (Figure 6a and $b$; inset) and the pan probe for QKI (Figure 6a and b)). MBP was not affected in the white matter and MOBP was not affected in the hippocampus (not shown). MAG showed negligible gene expression $(p<0.001)$ in both brain regions of the MAG null mice. The gene expression of the majority of cell cycle genes was not affected. The mRNA levels of $\mathrm{p} 57^{\text {Kip2 }}$ were significantly

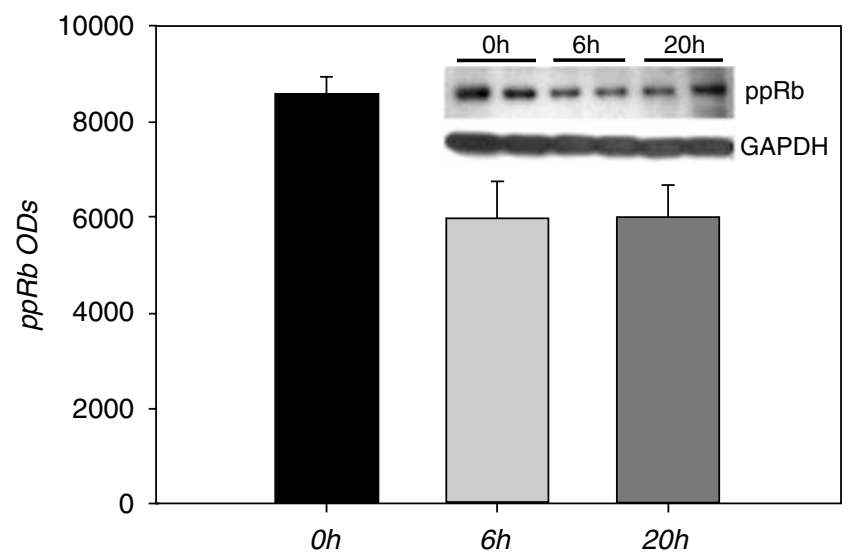

Figure 3 Stability of phosphorylated $(S 807 / 8 \mathrm{II})$ retinoblastoma protein-ppRb $(5807 / 8 \mathrm{I} I)$ in the white matter of $q k^{\mathrm{e} 5}$ mice measured by western blot. Brain samples from the same animal were either immediately frozen or stored for 6 and $20 \mathrm{~h}$ at room temperature to compare abundance of ppRb (S807/8I I). ppRb ODs - optical densities of ppRb normalized to the background. Data expressed as means \pm SEM. decreased in the hippocampus (Figure 6b), but not in the white matter of MAG null mice, suggesting that this decrease is unlikely to be associated with OLGs.

\section{DISCUSSION}

The studies described above were performed in the anterior cingulate cortex, the region where the most dramatic changes in the expression of myelin-specific markers were demonstrated previously in persons with SZ (Katsel et al, 2005b; Dracheva et al, 2006). Analysis of the microarray data from this region using the Ingenuity Pathway database revealed the consistent presence of canonical cell cycle pathways among the top networks and molecular functions affected in SZ (Figure 1). Correlation matrices (Table 3) between the mRNA levels of the top five affected cell cycle proteins and the levels of the cell-specific markers in persons with SZ and controls reveal two major findings. Firstly, the complex relationship between Cdk inhibitors and cyclins on one side, and neuronal or glial markers on the other, were significantly compromised in SZ relative to controls. Specifically, the relationships between cell cycle proteins and glial markers were only residually sustained and the relationships between cell cycle proteins and neuronal markers were generally absent. Secondly, strong statistically significant negative correlations between the levels of the measured neuronal and glial markers in the comparison group were absent in the SZ group. These findings suggest, that in the ACG of persons with SZ the normal relationships between neuronal and oligodendroglial gene expression are dissociated from each other and that the changes in gene expression of cell cycle proteins in SZ are likely to be associated with postmitotic myelinating OLGs. It is noteworthy that, these observations generalized not only for PMP22 and SOX10, but for multiple other myelin/OLG specific markers (eg, CNP, MAG, PLP, MBP (data not shown)), which we assessed in additional exploratory analyses. The fact that GFAP, an astrocytic marker, also showed a significant correlation with cyclin D1
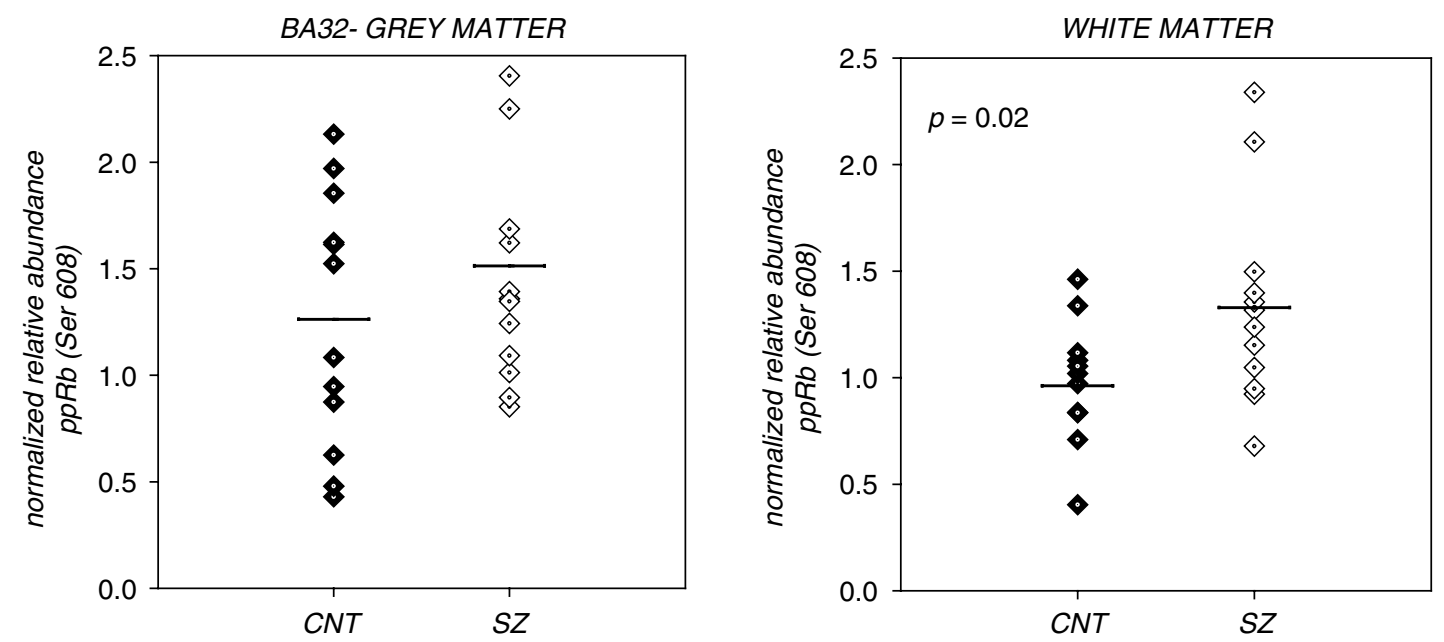

Figure 4 Relative abundance of phosphorylated (Ser608) retinoblastoma protein in the gray matter of ACG and the white matter of patients with SZs. Expression of ppRb (Ser608) was measured by western blot. Data expressed as means of ppRb (Ser608) ODs normalized to the underphosphorylated pRb and GAPDH and to the amount of total protein ( $N=12$ /group). Plot displays the group means (horizontal line). 

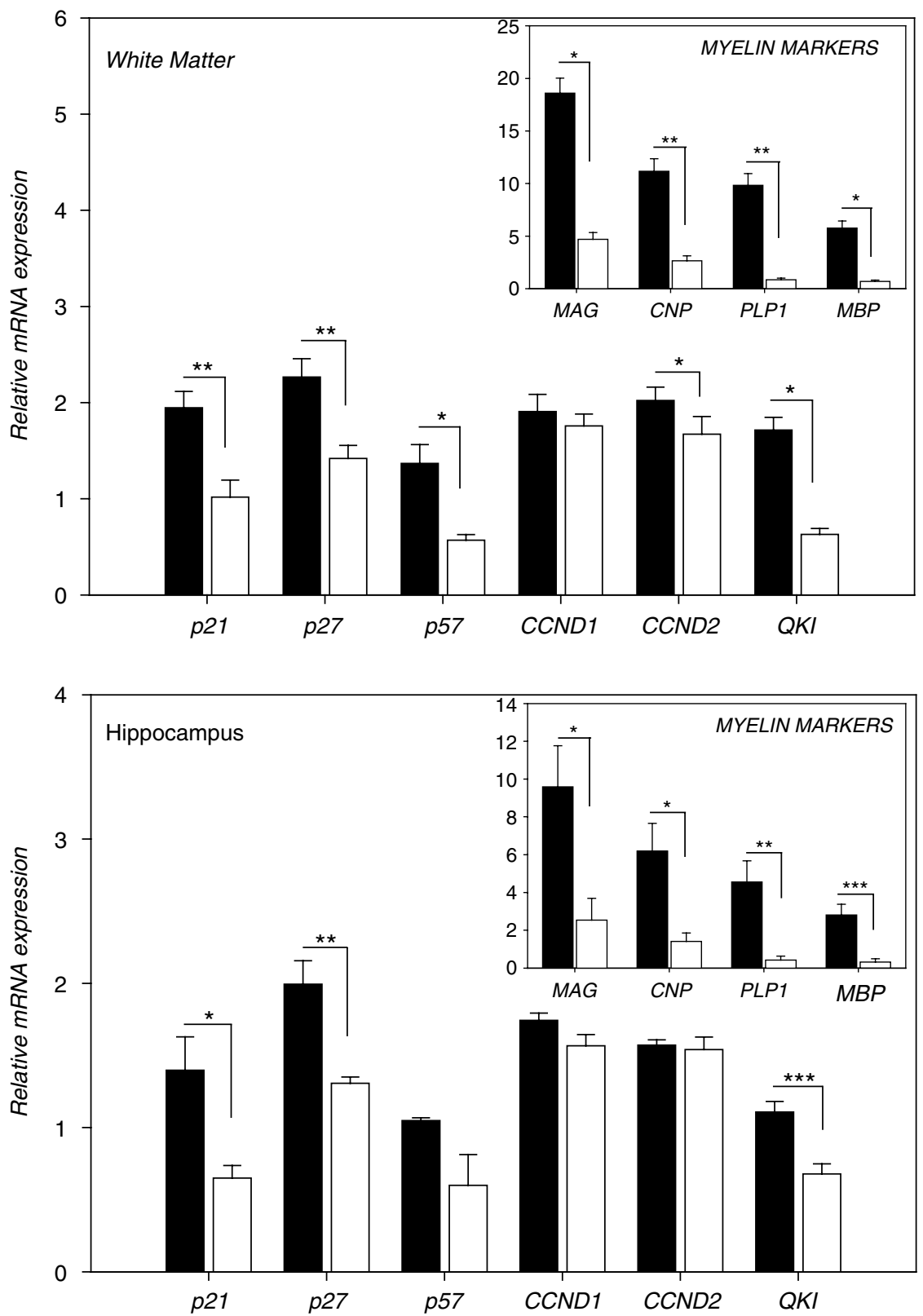

Figure 5 Relative mRNA expression of GI/S checkpoint genes and myelin proteins in the white matter and the hippocampus of quaking ( $q k^{\mathrm{e}}{ }^{5}$ ) mice. Gene expression was measured by GPCR. Data expressed as geometric means of individual expression values normalized to two housekeeping genes \pm SEM. Inserts showed gene expression of myelin-specific proteins. Wild type (black bars) and $q k^{\mathrm{e} 5}$ (white bars) mice ( $\left.N=4 / g r o u p\right)$. ${ }^{*} p s<0.05$, **⿻丷木大 $\mathrm{ps}<0.01$, ***** $\mathrm{ps}<0.001$.

in SZ (Table 5) may also implicate the involvement of astrocytes. However, a recent study reported the existence of mixed phenotype myelin marker-positive glia that also expressed GFAP (Dyer et al, 2000). The population of these cells has been shown to be dramatically increased under different pathologic conditions. Another astrocyte marker, PEA15, $15 \mathrm{kDa}$, a phosphoprotein enriched in astrocytes, was not correlated (data not shown) with any of the tested genes, refuting the involvement of astrocytes.

Gene expression changes for four cell cycle proteins were validated by qPCR. We conditionally subdivided them into two groups by their time-dependent involvement in cell cycle activation: G1/S phase transition and G1/S checkpoint. The first group included the Cdk inhibitor, $\mathrm{p} 57^{\mathrm{Kip} 2}$ and cyclin D1, which are the early regulators of the G1 phase entry and their mutually opposing activities are decisive for G1/S phase transition. The second group, the G1/S checkpoint genes, included TFDP1 and NPAT, the nuclear protein ataxia-telangiectasia locus. TFDP1 is a dimerization partner of the E2F transcription factor and when in complex with E2F, activates transcription of cell cycle proteins necessary for DNA replication and proliferation. NPAT is a primary substrate for cyclin E/Cdk2 complex and is essential for histone gene expression and $S$ phase entry (Zhao et al, 2000; Gao et al, 2003). The changes observed in the identified cell cycle genes are particularly interesting because two of these genes, CCND1 and $\mathrm{p} 57^{\mathrm{Kip} 2}$, have been shown to be among the early regulated cell cycle genes in 

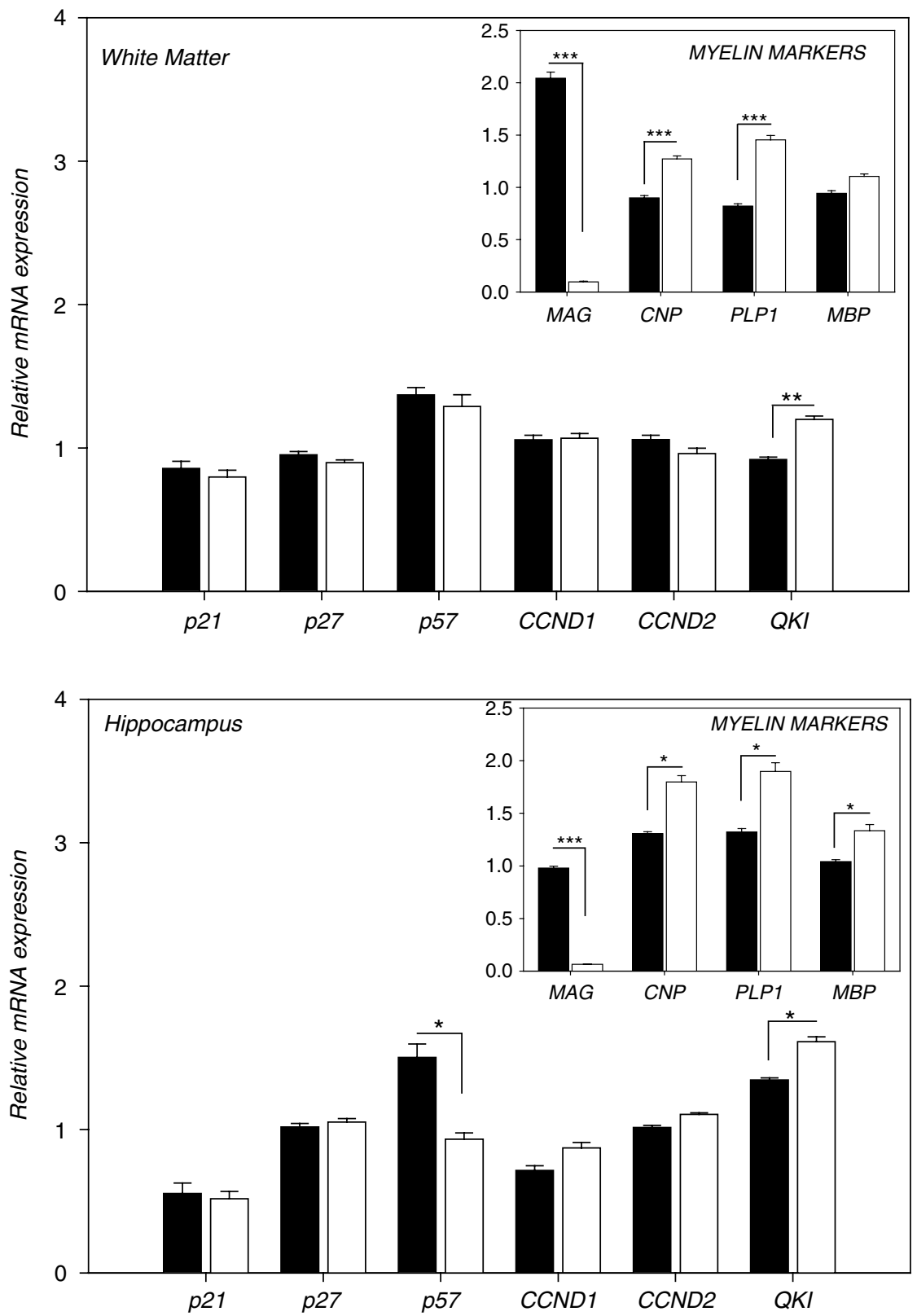

Figure 6 Relative mRNA expression of GI/S checkpoint genes and myelin proteins in the white matter and the hippocampus of MAG null mice. Gene expression was measured by qPCR. Data expressed as geometric means of individual expression values normalized to two housekeeping genes \pm SEM. Inserts showed gene expression of myelin-specific proteins. Wild type (black bars) and MAG null (white bars) mice ( $N=8 /$ group). *ps $<0.05$, *** $p s<0.0$ I, ***** $\mathrm{ps}<0.001$

OPCs after withdrawal of mitogen and exposure to thyroid hormones and thus may be central to OLG differentiation (Dugas et al, 2006, 2007).

Neuroleptic exposure is a confounding factor in postmortem studies of SZ and therefore can contribute to the detected gene expression abnormalities of the cell cycle proteins. However, comparison of controls with the subgroup of SZ subjects who were free of anti-psychotic medication for 4 weeks or more prior to death suggests that the acute effects of neuroleptic treatment are an unlikely basis for the detected gene expression abnormalities. Although it can be argued that a few weeks, months or years of neuroleptic washout may not compensate for years of exposure to neuroleptics, this argument appears less germane to cell cycle gene expression, which in theory, could be responsive to more short-term biological triggers. A recently published study also supports the data presented here (Table 6 and Figure 1) by suggesting that at least one antipsychotic drug, quetiapine, facilitates the development of OLGs rather than affecting them adversely (Xiao et al, 2007). However, the possibility of neuroleptic exposure confounds cannot be ruled out since it is possible that under some conditions, once cell cycle reentry has been triggered, continued exposure to the triggering mechanism(s) may not be obligatory (Yang et al, 2006; Herrup and Yang, 2007). In addition, a multiplicity of other environmental and nondisease-related factors, such as the possibility of environmental impoverishment, distinguishes 


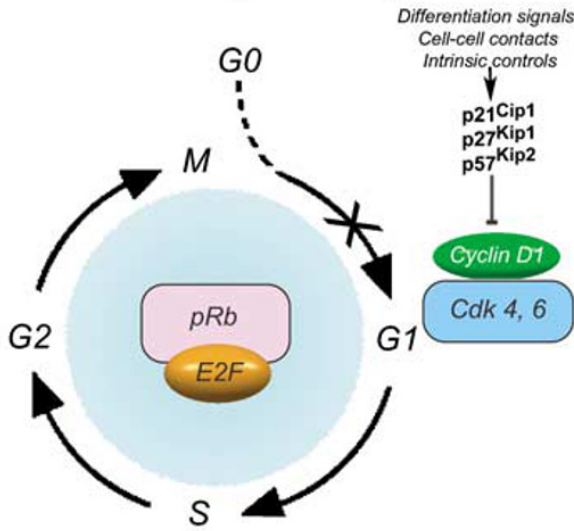

b

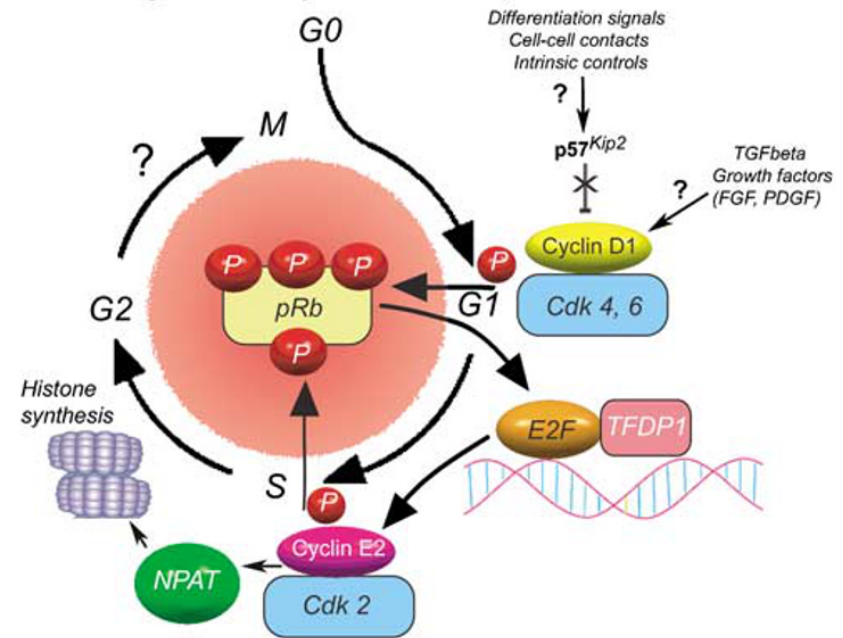

Figure 7 Hypothetical diagram of cell cycle re-entry in postmitotic oligodendrocytes in schizophrenia. (a) In normal postmitotic OLGs abundant expression of Cdk inhibitors: p2 $\left.\right|^{\text {Cipl }}, p 27^{\text {Kipl }}$, and $p 57^{\text {Kip2 }}$ maintain cell cycle arrest by inhibiting formation of cyclins $D$ and $E / C d k 2,4$, and 6 complexes. Low activity of cyclins/CDK complexes sustains pRb in the underphosphorylated state and guarantees its cell cycle suppression activity. (b) In postmitotic OLGs in persons with SZ, gene expression of $\mathrm{p} 57^{\mathrm{Kip} 2}$ is decreased which relieves inhibition of Cdk/cyclin D complex formation. Activated cyclin DI/Cdk4 complexes carry out phosphorylation of $\mathrm{pRb}$ and subsequent liberation of E2F transcription factors. E2F in complex with TFDPI initiates transcription of multiple cell cycle proteins, including cyclin E2. Activity of cyclin E2/Cdk2 complexes completes GI/S phase transition and initiates histone gene expression necessary for DNA replication to occur, via its substrate NPAT.

persons with SZ from the general population. The contribution of these extrinsic factors must be considered seriously in all neurobiological studies of SZ.

Myelin mutant mice were analyzed to determine whether they exhibited OPC/OLG-related cell cycle abnormalities similar to those observed in ACG in SZ subjects. Gene expression was compared in two myelin mutant animal models: quaking and MAG-null mice. Quaking mice, characterized by profound hypomyelination, and decreased gene expression of 10 myelin/OLG-specific proteins, showed significant downregulation in gene expression of Cip/Kip family of Cdk inhibitors in the white matter, and hippocampus (Figure 5) as well as frontal cortex (not shown). This observation suggests that OLG(s)-related cell cycle abnormalities may underlie the myelin deficits in these mutant mice. The finding that gene expression of cyclin D2 was also decreased in the white matter of quaking mice was somewhat intriguing. This decrease, however, was not detected in the hippocampus or frontal cortex of quaking mice, suggesting that the CCND2 downregulation is OLG-specific and possibly regulated at least in part by the QKI proteins. Interestingly, it has been shown that the coding region of six different cyclin genes contain consensus-binding regions for the QKI proteins (Larocque et al, 2005).

MAG, on the other hand, is a structural myelin protein and its adaxonal localization is suggestive of its involvement in the interactions between axons and myelin sheaths (Arquint et al, 1987; Attia et al, 1989). MAG-deficient mice evidence multiple subtle defects, including delayed CNS myelination, multiple myelin wrappings, defective longterm maintenance of myelin in aged mice, altered morphology of axons, and behavioral defects ( $\mathrm{Li}$ et al, 1994; Bartsch, 1996; Bartsch et al, 1997). In contrast to quaking mice, MAG knockout mice were characterized by elevated mRNA levels of most of the ten myelin/OLGspecific proteins (Figure 6, inset) without significant changes in gene expression of cell cycle genes in the white matter (Figure 6a). Overall, the studied gene expression profile of these two different myelin mutant animal models demonstrated that cell-cycle gene expression changes are not a necessary consequence of the reduced expression of oligodendrocyte-specific genes, such as MAG, but that genes that are known to modulate cell cycle activity during oligodendrocytes development (eg, QKI proteins) can significantly impair the expression of multiple myelin genes, including those that are affected in SZ. These observations suggest that cell cycle gene and protein abnormalities are not merely a consequence of the abnormal expression of myelin-associated genes. Taken together, these observations raise the possibility that global deficits in the expression of myelin-associated genes are likely to be a result of abnormalities in the expression of cell cycle genes and proteins. Clearly, this is not the only possible conclusion, but these results suggest that comparison of gene expression in animal models with specific gene expression defects may be a fruitful approach to the analysis of cause and effect relationships between myelin gene expression deficits and abnormalities in the expression of cell cycle genes.

The increased gene expression of cyclin D1 and the downregulation of $\mathrm{p} 57^{\mathrm{Kip} 2}$ - the inhibitor of CCND1/Cdk4,6 complexes in ACG of subjects with SZ may be due to the reentry of postmitotic OLGs into the G1 phase of the mitotic cell cycle. In the quiescent postmitotic state, $\mathrm{pRbs}$ act as checkpoint suppressors) for G1/S phase transition by entrapping E2F proteins, which are essential for transcription of multiple cyclins, CDKs, and enzymes involved in DNA replication. This proliferative/suppressive activity of the pRbs is relieved by the cyclin/Cdk complex-dependent phosphorylation of $\mathrm{pRb}$ at multiple serine/threonine sites. Hyperphosphorylated pRbs release E2F proteins and complete the transition from G1 to $S$ phase of the mitotic cell cycle. Our data demonstrated a significant increase in the abundance of the $\mathrm{ppRb}$ protein in quaking mutant mice, which was consistent with the decreased gene expression of 
major Cdk inhibitors in the OLGs of quaking mice. These findings further suggest that hypomyelination of the CNS may be the result of incomplete differentiation of OLG progenitors. Furthermore, the current findings of a significant increase in CCND/Cdk4-specific phosphorylation (Ser608) of $\mathrm{pRb}$ in the white matter of $\mathrm{SZ}$ subjects (Figure 4) provides additional evidence for the premise that SZ-associated changes in gene expression of cell cycle proteins are likely to occur in OLGs. Although the increase in $\mathrm{ppRb}$ in $\mathrm{SZ}$ was not as profound as that observed in quaking mice, a lesser increase in ppRb levels in $S Z$ is consistent with the fact that myelin-associated gene expression deficits in SZ are far less profound than the nearly complete suppression of myelin-associated gene expression in quaking mice.

The current findings raise several questions: if the activation of cell cycle pathways takes place in SZ, what happens to the mitotically reactivated OLGs and what is the morphologic and molecular evidence supporting this reactivation? Cell cycle activation of postmitotic cells is tightly guarded by the checkpoint mechanism, which not only prevents cell proliferation but is also tightly coupled to apoptosis and eventual cell cycle-related death (Herrup and Yang, 2007). Therefore, at least two possibilities can exist for mitotically reactivated OLGs. The first possibility is that the initiation of apoptotic mechanisms would eventually lead to cell death and subsequent reduction of OLG densities in SZ. The second possibility is that apoptosis does not take place and mitotically reactivated OLGs continue their transition from G1 to other phases of the canonical cell cycle. This should eventually lead to mitosis and a subsequent increase in the proliferation rate of OLGs, suggesting increased number of OLGs in ACG of SZ subjects.

Our microarray data (Katsel et al, 2005b) from ACG and other brain regions of subjects with SZ indicate decreases in mRNA levels of many of the pro-apoptotic genes. Reports of similar findings from other gene expression studies in different brain regions of subjects with SZ (Benes et al, 2006) further substantiate the current data. Reduced DNA fragmentation (Benes et al, 2003) and lack of reduction in OLG density in the ACG in SZ (Segal et al, 2006) refute the concurrent activation of the apoptotic process in oligodendrocytes in SZ. In contrast, other research has shown a decrease in the number of glial cells in the ACG in subjects with SZ (Stark et al, 2004). Timing of typical apoptotic process $(\sim 12 \mathrm{~h})$ predicts a rapid death for the affected cell population, which should result in devastating cell losses with disease progression. Imaging and postmortem morphometric studies do not support such a devastating loss of white matter and also argue against a persistent and profound apoptotic process in SZ. Alternatively, mitotically activated differentiated cells may persist in a transitional state between cell cycle re-entry and cell death. For example, it has been reported that cycling postmitotic but functionally deficient neurons (sometimes termed 'undead') can persist in the brains of animal models with neurodegenerative diseases for a long period of time (Yang et al, 2006).

Another possibility for mitotically reactivated OLGs is to complete the cell cycle, which culminates in cell division and ultimately increases the number of mitotically active cells. Such a mechanism has been posited to exist in the brains of aged non-human primates (Peters, 2002; Peters and Sethares, 2003, 2004; Hinman et al, 2006). As such, another question that needs to be addressed is identifying the specific markers that distinguish these mitotically active cells. We (Hakak et al, 2001; Katsel et al, 2005b; Dracheva et al, 2006) and others (Tkachev et al, 2003; Aston et al, 2004) have previously reported decreases in gene expression in the majority of the late markers of OLG differentiation (Dugas et al, 2006), including MAG, MOG, MAL, TF, and TM4SF11 in multiple brain regions of SZ subjects. Microarray and qPCR data indicate that the gene expression of early markers of OLG differentiation (Hakak et al, 2001; Tkachev et al, 2003; Aston et al, 2004; Katsel et al, 2005b; Dracheva et al, 2006; Dugas et al, 2006), specifically, CNP, CLDN11, and CD9, was also significantly decreased in multiple brain regions, and PLP1 was decreased in ACG (microarray data, unpublished) and in PFC (Tkachev et al, 2003 ) in SZ. Gene expression of MBP was not changed in the current datasets, although others have demonstrated significant decreases in SZ (Tkachev et al, 2003). Therefore, it is unlikely that mitotically reactivated OLGs retain the ability to express these OLG-specific proteins. Nevertheless, it remains possible that mitotically reactivated oligodendrocytes are functionally deficient and express abnormally low levels of OLG-specific genes. This possibility can be addressed empirically in future studies.

Although to date, the signaling pathway(s) that induce cell cycle re-entry in OLGs remains unclear, one of many empirically testable hypotheses is schematized in Figure 7. This figure outlines a hypothetical sequence of events that is consistent with the data presented above. In postmitotic OLGs (Figure 7a), cell cycle activity is suppressed. Intrinsic control systems, maintain high levels of the Cip/Kip family of Cdk inhibitors (p21 ${ }^{\mathrm{Cip} 1}, \mathrm{p} 27^{\mathrm{Kip} 1}$, and p57 ${ }^{\mathrm{Kip} 2}$ ), which keep the formation of cyclin D/E- Cdk complexes under control, thus sustaining dephosphorylated $\mathrm{pRb}$ in the proliferationsuppression state. In SZ, postmitotic OLGs may undergo 'dedifferentiation' transformation (Figure $7 \mathrm{~b}$ ). Increased levels of cyclin D1 and reduced levels of p5 $7^{\mathrm{Kip} 2}$, resulting from elevated levels of mitogen or growth factors, or withdrawal of differentiation factors, promote formation of CCND1/Cdk4, six complexes, and increase phosphorylation of $\mathrm{pRb}$ and subsequent release of E2F transcription factor. E2F, in combination with TFDP1, initiate transcription of cyclin E2, and formation of CCNE2/Cdk2 complexes. The increased activity of CCNE2/Cdk2 complexes ensure phosphorylation of $\mathrm{pRb}$ and upregulation of NPAT, the protein necessary for DNA replication to occur, thus carrying out transition to the $S$ phase. Whether DNA replication takes place and cells transition to the next phase(s) of mitotic cell cycle remain unanswered. Nevertheless, the detected profound abnormalities in the canonical cell cycle pathways in postmitotic OLGs are indicative of cell cycle re-entry, diverting OLGs from their postmitotic specialization and thus may be one of the bases for myelinassociated deficits in SZ.

\section{ACKNOWLEDGEMENTS}

This study was supported by NIH Grants MH064673, MH66392, VA Merit award to VH and by the VISN3 Mental Illness Research and Education Clinical Center (MIRECC). 


\section{DISCLOSURE/CONFLICT OF INTEREST}

Dr Davis reports that his wife Bonnie Morrison Davis, MD has received royalty income from her patent, which is licensed to Janssen Pharmaceuticals, a subsidiary of Johnson \& Johnson and Shire Pharm. Other authors declare that no financial support or compensation has been received from any individual or corporate entity over the past 3 years for research or professional service and there are no personal financial holdings that could be perceived as constituting a potential conflict of interest.

\section{REFERENCES}

Aberg K, Saetre P, Jareborg N, Jazin E (2006a). Human QKI, a potential regulator of mRNA expression of human oligodendrocyte-related genes involved in schizophrenia. Proc Natl Acad Sci USA 103: 7482-7487.

Aberg K, Saetre P, Lindholm E, Ekholm B, Pettersson U, Adolfsson R et al (2006b). Human QKI, a new candidate gene for schizophrenia involved in myelination. Am J Med Genet B Neuropsychiatr Genet 141: 84-90.

Arnold SE, Trojanowski JQ (1996). Recent advances in defining the neuropathology of schizophrenia. Acta Neuropathol (Berl) 92: 217-231.

Arquint M, Roder J, Chia LS, Down J, Wilkinson D, Bayley $\mathrm{H}$ et al (1987). Molecular-cloning and primary structure of myelinassociated glycoprotein. Proc Natl Acad Sci USA 84: 600-604.

Aston C, Jiang L, Sokolov BP (2004). Microarray analysis of postmortem temporal cortex from patients with schizophrenia. J Neurosci Res 77: 858-866.

Attia J, Tropak M, Johnson PW, Newerly-Abranow W, Pawson T, Roder JC et al (1989). Modulated adhesion: a proposal for the role of myelin-associated glycoprotein in myelin wrapping. Clin Chem 35: 717-720.

Bahn S, Jones PB (2003). Gene expression in schizophrenia and bipolar disorder. Schizo Res 60: 60.

Barta PE, Pearlson GD, Powers RE, Richards SS, Tune LE (1990). Auditory hallucinations and smaller superior temporal gyral volume in schizophrenia. Am J Psychiatry 147: 1457-1462.

Bartsch S, Montag D, Schachner M, Bartsch U (1997). Increased number of unmyelinated axons in optic nerves of adult mice deficient in the myelin-associated glycoprotein (MAG). $\mathrm{Br}$ Res 762: 231-234.

Bartsch U (1996). Myelination and axonal regeneration in the central nervous system of mice deficient in the myelinassociated glycoprotein. J Neurocytol 25: 303-313.

Bartzokis G, Nuechterlein KH, Lu PH, Gitlin M, Rogers S, Mintz J (2003). Dysregulated brain development in adult men with schizophrenia: a magnetic resonance imaging study. Biol Psychiatry 53: 412-421.

Baumann N, Pham-Dinh D (2001). Biology of oligodendrocyte and myelin in the mammalian central nervous system. Physiol Rev 81: 871-927.

Benes FM (1989). Myelination of cortical-hippocampal relays during late adolescence. Schizophr Bull 15: 585-593.

Benes FM (1999). Evidence for altered trisynaptic circuitry in schizophrenic hippocampus. Biol Psychiatry 46: 589-599.

Benes FM, Davidson J, Bird ED (1986). Quantitative cytoarchitectural studies of the cerebral cortex of schizophrenics. Arch Gen Psychiatry 43: 31-35.

Benes FM, Matzilevich D, Burke RE, Walsh J (2006). The expression of proapoptosis genes is increased in bipolar disorder, but not in schizophrenia. Mol Psychiatry 11: 241-251.

Benes FM, Turtle M, Khan Y, Farol P (1994). Myelination of a key relay zone in the hippocampal formation occurs in the human brain during childhood, adolescence, and adulthood. Arch Gen Psychiatry 51: 477-484.

Benes FM, Vincent SL, Todtenkopf M (2001). The density of pyramidal and nonpyramidal neurons in anterior cingulate cortex of schizophrenic and bipolar subjects. Biol Psychiatry 50: 395-406.

Benes FM, Walsh J, Bhattacharyya S, Sheth A, Berretta S (2003). DNA fragmentation decreased in schizophrenia but not bipolar disorder. Arch Gen Psychiatry 60: 359-364.

Benjamini Y, Hochberg Y (1995). Controlling the false discovery rate - a practical and powerful approach to multiple testing. $J$ R Soc Ser B (Methodol) 57: 289-300.

Bolstad BM, Irizarry RA, Astrand M, Speed TP (2003). A comparison of normalization methods for high-density oligonucleotide array data based on variance and bias. Bioinformatics 19: 185-193.

Buchsbaum MS, Tang CY, Peled S, Gudbjartsson H, Lu D, Hazlett EA et al (1998). MRI white matter diffusion anisotropy and PET metabolic rate in schizophrenia. NeuroReport 9: 425-430.

Budhraja V, Spitznagel E, Schaiff WT, Sadovsky Y (2003). Incorporation of gene-specific variability improves expression analysis using high-density DNA microarrays. BMC Biol 1: 1 .

Cotter D, Mackay D, Landau S, Kerwin R, Everall I (2001). Reduced glial cell density and neuronal size in the anterior cingulate cortex in major depressive disorder. Arch Gen Psychiatry 58: 545-553.

Davis KL, Mohs RC, Marin D, Purohit DP, Perl DP, Lantz M et al (1999). Cholinergic markers in elderly patients with early signs of Alzheimer disease. JAMA 281: 1401-1406.

Davis KL, Stewart DG, Friedman JI, Buchsbaum M, Harvey PD, Hof $\mathrm{P}$ et al (2003). White matter changes in schizophrenia: Evidence for myelin-related dysfunction. Arc Gen Psychiatry 60: 443-456.

Dracheva S, Davis KL, Chin B, Woo DA, Schmeidler J, Haroutunian V (2006). Myelin-associated mRNA and protein expression deficits in the anterior cingulate cortex and hippocampus in schizophrenia. Neurobiol Dis 79: 157-173.

Dracheva S, Marras SA, Elhakem SL, Kramer FR, Davis KL, Haroutunian V (2001). N-methyl-D-aspartic acid receptor expression in the dorsolateral prefrontal cortex of elderly patients with schizophrenia. Am J Psychiatry 158: 1400-1410.

Dracheva S, McGurk SR, Davis KL, Haroutunian V (2005). mRNA expression of AMPA receptors and AMPA receptor binding proteins in the cerebral cortex of of elderly schizophrenics. J Neurosci Res 79: 868-878.

Dugas JC, Ibrahim A, Barres BA (2007). A crucial role for p57Kip2 in the intracellular timer that controls oligodendrocyte differentiation. J Neurosci 27: 6185-6196.

Dugas JC, Tai YC, Speed TP, Ngai J, Barres BA (2006). Functional genomic analysis of oligodendrocyte differentiation. J Neurosci 26: 10967-10983.

Dyer CA, Kendler A, Jean-Guillaume D, Awatramani R, Lee A, Mason LM et al (2000). GFAP-positive and myelin markerpositive glia in normal and pathologic environments. J Neurosci Res 60: 412-426.

Flynn SW, Lang DJ, MacKay AL, Goghari V, Vavasour IM, Whittall KP et al (2003). Abnormalities of myelination in schizophrenia detected in vivo with MRI, and post-mortem with analysis of oligodendrocyte proteins. Mol Psychiatry 8: 811-820.

Foong J, Maier M, Barker GJ, Brocklehurst S, Miller DH, Ron MA (2000). In vivo investigation of white matter pathology in schizophrenia with magnetisation transfer imaging. J Neurol Neurosurg Psychiatr 68: 70-74.

Foong J, Symms MR, Barker GJ, Maier M, Woermann FG, Miller DH et al (2001). Neuropathological abnormalities in schizophrenia: evidence from magnetization transfer imaging. Brain 124: 882-892. 
Franklin KBJ, Paxinos G (1997). The Mouse Brain in Stereotaxic Coordinates. Academic Press: New York.

Friston KJ, Frith CD (1995). Schizophrenia: a disconnection syndrome? Clin Neurosci 3: 89-97.

Gallo V, Ghiani CA (2000). Glutamate receptors in glia: new cells, new inputs and new functions. Trends Pharmacol Sci 21: 252-258.

Gao G, Bracken AP, Burkard K, Pasini D, Classon M, Attwooll C et al (2003). NPAT expression is regulated by E2F and is essential for cell cycle progression. Mol Cell Biol 23: 2821-2833.

Geng Y, Eaton EN, Picon M, Roberts JM, Lundberg AS, Gifford A et al (1996). Regulation of cyclin E transcription by E2Fs and retinoblastoma protein. Oncogene 12: 1173-1180.

Giedd JN, Blumenthal J, Jeffries NO, Castellanos FX, Liu H, Zijdenbos A et al (1999). Brain development during childhood and adolescence: a longitudinal MRI study. Nat Neurosci 2: 861-863.

Goldman-Rakic PS (1999). The physiological approach: functional architecture of working memory and disordered cognition in schizophrenia. Biol Psychiatry 46: 650-661.

Goldman-Rakic PS, Selemon LD (1997). Functional and anatomical aspects of prefrontal pathology in schizophrenia. Schizophr Bull 23: 437-458.

Hakak Y, Walker JR, Li C, Wong WH, Davis KL, Buxbaum JD et al (2001). Genome-wide expression analysis reveals dysregulation of myelination-related genes in chronic schizophrenia. Proc Natl Acad Sci USA 98: 4746-4751.

Haroutunian V, Davis KL (2000). Neuropathology of schizophrenia. In: Breier A, Tran PV, Herrera J, Bymaster F, Tollefson GD (eds). Current Issues in the Psychopharmacology of Schizophrenia. Williams and Wilkins: Baltimore. pp 57-70.

Haroutunian V, Davies PJ, Vianna C, Buxbaum JD, Purohit DP (2006a). Tau protein abnormalities associated with the progression of Alzheimer disease type dementia. Neurobiol Aging 28: $1-7$.

Haroutunian V, Katsel P, Dracheva S, Davis KL (2006b). The human homolog of QKI gene affected in the severe dysmyelination 'quaking' mouse phenotype is downregulated in multiple brain regions in schizophrenia. Am J Psychiat 163: 1834-1837.

Haroutunian V, Katsel P, Schmeidler J (2007). Transcriptional vulnerability of brain regions in Alzheimer's disease and dementia. Neurobiol Aging, advance online publication; doi:10.1016/j.neurobiolaging.2007.07.021.

Haroutunian V, Perl DP, Purohit DP, Marin D, Khan K, Lantz M et al (1998). Regional distribution of neuritic plaques in the nondemented elderly and subjects with very mild Alzheimer disease. Arch Neurol 55: 1185-1191.

Haroutunian V, Purohit DP, Perl DP, Marin D, Khan K, Lantz M et al (1999). Neurofibrillary tangles in nondemented elderly subjects and mild Alzheimer disease. Arch Neurol 56: 713-718.

Harrison PJ (1999). The neuropathology of schizophrenia. A critical review of the data and their interpretation. Brain 122(Part 4): 593-624.

Herrup K, Yang Y (2007). Cell cycle regulation in the postmitotic neuron: oxymoron or new biology? Nat Rev Neurosci 8: 368-378.

Hinman JD, Peters A, Cabral H, Rosene DL, Hollander W, Rasband MN et al (2006). Age-related molecular reorganization at the node of Ranvier. J Comp Neurol 495: 351-362.

Hof PR, Haroutunian V, Friedrich Jr VL, Byne W, Buitron C, Perl DP et al (2003). Loss and altered spatial distribution of oligodendrocytes in the superior frontal gyrus in schizophrenia. Biol Psychiatry 53: 1075-1085.

Huttenlocher PR (1979). Synaptic density in human frontal cortex - developmental changes and effects of aging. Brain Res 163: 195-205.

Irizarry RA, Hobbs B, Collin F, Beazer-Barclay YD, Antonellis KJ, Scherf U et al (2003). Exploration, normalization, and summaries of high-density oligonucleotide array probe level data. Biostatistics 4: 249-264.

Iwamoto $\mathrm{K}$, Bundo $\mathrm{M}$, Yamada $\mathrm{K}$, Takao $\mathrm{H}$, Iwayama-Shigeno $\mathrm{Y}$, Yoshikawa T et al (2005). DNA methylation status of SOX10 correlates with its downregulation and oligodendrocyte dysfunction in schizophrenia. J Neurosci 25: 5376-5381.

Katsel P, Davis KL, Gorman JM, Haroutunian V (2005a). Variations in differential gene expression patterns across multiple brain regions in schizophrenia. Schizo Res 77: 241-252.

Katsel P, Davis KL, Haroutunian V (2004). Large-scale microarray studies of gene expression in multiple regions of the brain in schizophrenia and Alzheimer's disease. Int Rev Neurobiol 63: 41-81.

Katsel P, Davis KL, Haroutunian V (2005b). Variations in myelin and oligodendrocyte-related gene expression across multiple brain regions: A gene ontology study. Schizo Res 79: 157-173.

Katsel P, Li C, Haroutunian V (2007). Gene expression alterations in the sphingolipid metabolism pathways during progression of dementia and Alzheimer's disease: a shift toward ceramide accumulation at the earliest recognizable stages of Alzheimer's disease? Neurochem Res 32: 845-856.

Katsel PL, Davis KL, Haroutunian V (2005c). Large-scale microarray studies of gene expression in multiple regions of the brain in schizophrenia and Alzheimer's disease. Int Rev Neurobiol 63 41-82.

Kornhuber J, Schultz A, Wiltfang J, Meineke I, Gleiter CH, Zochling $\mathrm{R}$ et al (1999). Persistence of haloperidol in human brain tissue. Am J Psychiatry 156: 885-890.

Kovelman JA, Scheibel AB (1984). A neurohistological correlate of schizophrenia. Biol Psychiatry 19: 1601-1621.

Larocca JN, Rodriguez-Gabin AG (2002). Myelin biogenesis: vesicle transport in oligodendrocytes. Neurochem Res 27: 1313-1329.

Larocque D, Galarneau A, Liu HN, Scott M, Almazan G, Richard S (2005). Protection of p27(Kip1) mRNA by quaking RNA-binding proteins promotes oligodendrocyte differentiation. Nat Neurosci 8: 27-33.

Li C, Tropak MB, Gerlai R, Clapoff S, Abramow-Newerly W, Trapp B et al (1994). Myelination in the absence of myelinassociated glycoprotein. Nature 369: 747-750.

Lim KO, Hedehus M, Moseley M, de Crespigny A, Sullivan EV, Pfefferbaum A (1999). Compromised white matter tract integrity in schizophrenia inferred from diffusion tensor imaging. Arch Gen psychiatry 56: 367-374.

Liu Y, Wu Y, Lee JC, Xue H, Pevny LH, Kaprielian Z et al (2002). Oligodendrocyte and astrocyte development in rodents: an in situ and immunohistological analysis during embryonic development. Glia 40: 25-43.

Lundberg AS, Weinberg RA (1998). Functional inactivation of the retinoblastoma protein requires sequential modification by at least two distinct cyclin-cdk complexes. Mol Cell Biol 18: 753-761.

Mariani TJ, Budhraja V, Mecham BH, Gu CC, Watson MA, Sadovsky Y (2003). A variable fold change threshold determines significance for expression microarrays. FASEB $J$ 17: 321-323.

Meyer-Lindenberg A, Poline JB, Kohn PD, Holt JL, Egan MF, Weinberger DR et al (2001). Evidence for abnormal cortical functional connectivity during working memory in schizophrenia. Am J Psychiatry 158: 1809-1817.

Mirra SS, Heyman A, McKeel D, Sumi SM, Crain BJ, Brownlee LM et al (1991). The consortium to establish a registry for Alzheimer's disease (CERAD). Part II. Standardization of the neuropathologic assessment of Alzheimer's disease. Neurology 41: 479-486.

Mitkus SN, Hyde TM, Vakkalanka R, Kolachana B, Weinberger DR, Kleinman JE et al (2008). Expression of oligodendrocyteassociated genes in dorsolateral prefrontal cortex of patients with schizophrenia. Schizophr Res 98: 129-138. 
Miyakawa T, Sumiyoshi S, Deshimaru M, Suzuki T, Tomonari H (1972). Electron microscopic study on schizophrenia. Mechanism of pathological changes. Acta Neuropathol (Berl) 20: 67-77.

Nikulina EM, Skrinskaya JA, Avgustinovich DF, Popova NK (1995). Dopaminergic brain system in the quaking mutant mouse. Pharmacol Biochem Behav 50: 333-337.

Noveroske JK, Hardy R, Dapper JD, Vogel H, Justice MJ (2005). A new ENU-induced allele of mouse quaking causes severe CNS dysmyelination. Mamm Genome 16: 672-682.

Pavlidis P, Lewis DP, Noble WS (2002). Exploring gene expression data with class scores. Pac Symp Biocomput 7: 474-485.

Pavlidis P, Qin J, Arango V, Mann JJ, Sibille E (2004). Using the gene ontology for microarray data mining: a comparison of methods and application to age effects in human prefrontal cortex. Neurochem Res 29: 1213-1222.

Peters A (2002). The effects of normal aging on myelin and nerve fibers: a review. J Neurocytol 31: 581-593.

Peters A, Sethares C (2003). Is there remyelination during aging of the primate central nervous system? J Comp Neurol 460: 238-254.

Peters A, Sethares C (2004). Oligodendrocytes, their progenitors and other neuroglial cells in the aging primate cerebral cortex. Cereb Cortex 14: 995-1007.

Purohit DP, Perl DP, Haroutunian V, Powchik P, Davidson M, Davis KL (1998). Alzheimer's disease and related neurodegenerative diseases in elderly patients with schizophrenia: a postmortem neuropathologic study of 100 cases. Arch Gen Psychiatry 55: 205-211.

Raedler TJ, Knable MB, Weinberger DR (1998). Schizophrenia as a developmental disorder of the cerebral cortex. Curr Opin Neurobiol 8: 157-161.

Rajkowska G, Miguel-Hidalgo JJ, Makkos Z, Meltzer H, Overholser J, Stockmeier C (2002). Layer-specific reductions in GFAP-reactive astroglia in the dorsolateral prefrontal cortex in schizophrenia. Schizophr Res 57: 127-138.

Rajkowska G, Selemon LD, Goldman-Rakic PS (1998). Neuronal and glial somal size in the prefrontal cortex: a postmortem morphometric study of schizophrenia and Huntington disease. Arch Gen Psychiatry 55: 215-224.

Roy K, Murtie JC, El-Khodor BF, Edgar N, Sardi SP, Hooks BM et al (2007). Loss of erbB signaling in oligodendrocytes alters myelin and dopaminergic function, a potential mechanism for neuropsychiatric disorders. Proc Natl Acad Sci USA 104: 8131-8136.

Segal D, Haroutunian V, Schmitz C, Hof P (2006). Spatial distribution and density of oligodendrocytes in the cingulum bundle is unaltered in schizophrenia. Abstr Soc Neurosci.

Selemon LD, Goldman-Rakic PS (1999). The reduced neuropil hypothesis: a circuit based model of schizophrenia. Biol Psychiatry 45: 17-25.

Selemon LD, Rajkowska G (2003). Cellular pathology in the dorsolateral prefrontal cortex distinguishes schizophrenia from bipolar disorder. Curr Mol Med 3: 427-436.

Selemon LD, Rajkowska G, Goldman-Rakic PS (1998). Elevated neuronal density in prefrontal area 46 in brains from schizophrenic patients: application of a three-dimensional, stereologic counting method. J Comp Neurol 392: 402-412.
Stark AK, Uylings HB, Sanz-Arigita E, Pakkenberg B (2004). Glial cell loss in the anterior cingulate cortex, a subregion of the prefrontal cortex, in subjects with schizophrenia. Am J Psychiatry 161: 882-888.

Stevens JR (1973). An anatomy of schizophrenia? Arch Gen Psychiatry 29: 177-189.

Sugai T, Kawamura M, Iritani S, Araki K, Makifuchi T, Imai C et al (2004). Prefrontal abnormality of schizophrenia revealed by DNA microarray impact on glial and neurotrophic gene expression. Ann N Y Acad Sci 1025: 84-91.

Tamminga CA, Vogel M, Gao X, Lahti AC, Holcomb HH (2000). The limbic cortex in schizophrenia: focus on the anterior cingulate. Brain Res Brain Res Rev 31: 364-370.

Terry R, DeTeresa R, Hansen L (1987). Neocortical cell counts in normal human adult aging. Ann Neurol 21 No 6: 530-539.

Tkachev D, Mimmack ML, Ryan MM, Wayland M, Freeman T, Jones PB et al (2003). Oligodendrocyte dysfunction in schizophrenia and bipolar disorder. Lancet 362: 798-805.

Torrey EF, Peterson MR (1974). Schizophrenia and the limbic system. Lancet 2: 942-946.

Uranova N, Orlovskaya D, Vikhreva O, Zimina I, Kolomeets N, Vostrikov V et al (2001). Electron microscopy of oligodendroglia in severe mental illness. Brain Res Bull 55: 597-610.

Uranova NA, Vostrikov VM, Orlovskaya DD, Rachmanova VI (2004). Oligodendroglial density in the prefrontal cortex in schizophrenia and mood disorders: a study from the stanley neuropathology consortium. Schizo Res 67: 269-275.

Vostrikov VM, Uranova NA, Orlovskaya DD (2007). Deficit of perineuronal oligodendrocytes in the prefrontal cortex in schizophrenia and mood disorders. Schizophr Res 94: 273-280.

Weinberger DR (1995). Neurodevelopmental prespectives in schizophrenia. In: Bloom FE and Kupfer DJ (eds). Psychopharmacology: The Fourth Generation of Progress. Raven Press: New York. pp 1171-1184.

Weinberger DR (1999). Cell biology of the hippocampal formation in schizophrenia. Biol Psychiatry 45: 395-402.

Weinberger DR, Lipska BK (1995). Cortical maldevelopment, antipsychotic drugs, and schizophrenia: a search for common ground. Schizophr Res 16: 87-110.

Xiao L, Xu H, Zhang Y, Wei Z, He J, Jiang W et al (2007). Quetiapine facilitates oligodendrocyte development and prevents mice from myelin breakdown and behavioral changes. Mol Psychiatry, advance online publication 7 August 2007; doi:10.1038/sj.mp.4002064.

Yang Y, Varvel NH, Lamb BT, Herrup K (2006). Ectopic cell cycle events link human Alzheimer's disease and amyloid precursor protein transgenic mouse models. J Neurosci 26: 775-784.

Zarkowska T, Mittnacht S (1997). Differential phosphorylation of the retinoblastoma protein by G1/S cyclin-dependent kinases. J Biol Chem 272: 12738-12746.

Zeman W, Innes JRM (1963). Craigie's Neuroanatomy of the Rat. Academic Press: New York.

Zhao J, Kennedy BK, Lawrence BD, Barbie DA, Matera AG, Fletcher JA et al (2000). NPAT links cyclin E-Cdk2 to the regulation of replication-dependent histone gene transcription. Genes Dev 14: 2283-2297. 